\title{
The role of fiscal policy in Britain's Great Inflation is
}

\author{
Jingwen Fan ${ }^{\mathrm{a}}$, Patrick Minford ${ }^{\mathrm{b}}$, Zhirong $\mathrm{Ou}^{\mathrm{c}, *}$ \\ a Nottingham Trent University, United Kingdom \\ b Cardiff University and CEPR, United Kingdom \\ c Cardiff University, United Kingdom
}

\section{A R T I C L E I N F O}

\section{Article history:}

Received 19 January 2016

Received in revised form 4 May 2016

Accepted 27 May 2016

Available online 14 June 2016

\section{JEL classification:}

E31

E37

E62

E65

\section{Keywords:}

UK inflation

Fiscal Theory of the Price Level

Identification

Testing

Indirect inference

\begin{abstract}
A B S T R A C T
We investigate whether the Fiscal Theory of the Price Level (FTPL) can explain UK inflation in the 1970s. We confront the identification problem involved by setting up the FTPL as a structural model for the episode and pitting it against an alternative Orthodox model; the models have a reduced form that is common in form but, because each model is over-identified, numerically distinct. We use indirect inference to test which model could be generating the VECM approximation to the reduced form that we estimate on the data for the episode. Neither model is rejected, though the FTPL model substantially outperforms the Orthodox. But by far the best account of the period assumes that expectations were a probability-weighted combination of the two regimes. Fiscal policy has a substantial role in this weighted model in determining inflation. A similar model accounts for the 1980s but this role of fiscal policy is much diminished.
\end{abstract}

(c) 2016 Elsevier B.V. All rights reserved.

\section{Introduction}

In 1972 the UK government floated the pound while pursuing highly expansionary fiscal policies whose aim was to reduce rising unemployment. To control inflation the government introduced statutory wage and price controls. Monetary policy was given no targets for either the money supply or inflation; interest rates were held at rates that would accommodate growth and falling unemployment. Since wage and price controls would inevitably break down faced with the inflationary effects of such policies, this period appears to fit rather well with the policy requirements of the Fiscal Theory of the Price Level: fiscal policy appears to have been non-Ricardian (not limited by concerns with solvency) and monetary policy accommodative to inflation - in the language of Leeper (1991) fiscal policy was 'active' and monetary policy was 'passive'. Furthermore, there was no reason to believe that this policy regime would come to an end: both Conservative and Labour parties won elections in the 1970s and both pursued essentially the same

\footnotetext{
ts We are grateful to Jagjit Chadha, Juergen von Hagen, Eric Leeper and economics seminar participants in Cardiff, Kent and Plymouth universities, for useful comments on an earlier version. We are of course responsible for any remaining errors.

* Corresponding author at: B14, Aberconway Building, Cardiff Business School, Colum Drive, Cardiff CF10 3EU, United Kingdom.

E-mail address: OuZ@cardiff.ac.uk (Z. Ou).
}

policies. While Margaret Thatcher won the Conservative leadership in 1975 and also the election in 1979, during the period we study here it was not assumed that the monetarist policies she advocated would ever occur, since they were opposed by the two other parties, by a powerful group in her own party, as well as by the senior civil service. Only after her election and her actual implementation of them was this a reasonable assumption. So it appears that in the period from 1972 to 1979 there was a prevailing policy regime which was expected to continue. These are key assumptions about the policy environment; besides this narrative background we also check them empirically below. Besides investigating behaviour in the 1970 s, we go on to investigate the behaviour of the Thatcher regime in the 1980s, to test the popular assumption that this regime greatly changed the conduct of macroeconomic policy. According to this assumption there was a shift of regime towards 'monetarist' policy, in which monetary policy became 'active' and fiscal policy became 'passive' (or 'Ricardian'). Thus we broaden our analysis to put the 1970s episode into the context of the evolution of macroeconomic policy over this whole dramatic period of UK history.

Under FTPL the price level or inflation is determined by the need to impose fiscal solvency; thus it is set so that the market value of outstanding debt equals the expected present value of future primary surpluses. The FTPL has been set out and developed in Leeper (1991); Sims (1994); Woodford (1998a, 2001) and Cochrane (2001, 2005) - see also comments by McCallum (2001, 2003) and Buiter (1999, 2002), and for 
Table 1

Summary of the FTPL and Orthodox models.

\begin{tabular}{|c|c|c|}
\hline \multicolumn{3}{|l|}{ Common equations } \\
\hline $\begin{array}{l}\text { IS curve } \\
\text { Phillips curve } \\
\text { Productivity }\end{array}$ & & $\begin{array}{l}y_{t}-y_{t}^{*}=E_{t}\left(y_{t+1}-y_{t+1}^{*}\right)-\frac{1}{\sigma}\left(R_{t}^{S}-E_{t} \pi_{t+1}\right)+e r r_{t}^{I S} \\
\pi_{t}=\theta\left(y_{t}-y_{t}^{*}\right)+\beta E_{t} \pi_{t+1}+e r r_{t}^{P P} \\
y_{t}^{*}-y_{t-1}{ }^{*}=c^{y^{*}}+\gamma\left(y_{t-1}-y_{t-2}^{*}\right)+e r r_{t}^{y^{*}}\end{array}$ \\
\hline Distictive equations & FTPL & Orthodox \\
\hline $\begin{array}{l}\text { Fiscal policy } \\
\text { Inflation determination }\end{array}$ & $\begin{array}{l}\Delta\left(g_{t}-t_{t}\right)=e r r_{t}^{g-t} \\
\pi_{t}=\kappa\left(g_{t}-t_{t}\right)+c^{\pi}+e r r_{t}^{p i}\end{array}$ & $\begin{array}{l}\left.\Delta\left(g_{t}-t_{t}\right)=-\delta(g-t)_{t-1}-c^{g-t}\right]+e r r_{t}^{g-t^{\prime}} \\
R_{t}^{s}=(1-\rho)\left[r^{s}+\phi_{\Pi} \pi_{t}+\phi_{x g a p}\left(y_{t}-y_{t}^{*}\right)\right]+\rho R_{t-1}^{s}+e r r_{t}^{R^{s}}\end{array}$ \\
\hline
\end{tabular}

Note: all equation errors are assumed to follow an $A R(1)$ process.

surveys Kocherlakota and Phelan (1999); Carlstrom and Fuerst (2000) and Christiano and Fitzgerald (2000). Empirical tests have been proposed by Bohn (1998); Canzoneri et al. (2001) and Bajo-Rubio et al. (2014). Loyo (2000) for example argues that Brazilian policy in the late 1970s and early 1980s was non-Ricardian and that the FTPL provides a persuasive explanation for Brazil's high inflation during that time. The work of Tanner and Ramos (2003) also finds evidence of fiscal dominance for the case of Brazil for some important periods. Cochrane $(1999,2005)$ argues that the FTPL with a statistically exogenous surplus process explains the dynamics of U.S. inflation in the 1970s. This appears to be similar to what we see in the UK during the 1970s. In addition, there has been extensive work on FTPL in monetary unions ${ }^{1}$ and specifically on European economies. ${ }^{2}$

Our aim in this paper is to test the Fiscal Theory of the Price Level (FTPL) as applied to the UK in the 1970s episode we described above; and to contrast it with the apparently very different policy in the 1980 s. Cochrane $(1999,2001,2005)$ has noted that there is a basic identification problem affecting the FTPL: in the FTPL fiscal policy is exogenous and forces inflation to produce fiscal solvency. But similar economic behaviour can be consistent with an exogenous monetary policy determining inflation in the 'orthodox' way, with Ricardian fiscal policy endogenously responding to the government budget constraint to ensure solvency given that inflation path - what we will call the Orthodox model. Thus there is a besetting problem in the empirical literature we have cited above, that equations that appear to reflect the FTPL and are used to 'test' it, could also be implied by the Orthodox set-up. To put it more formally the reduced form or solved representation of an FTPL model may in form be indistinguishable from that of an orthodox model; this is true of both single-equation implications of the model and complete solutions of it.

As Bajo-Rubio et al. (2014) note, the tests are focused on the government's intertemporal budget constraint. In the 'backwardlooking' version (Bohn, 1998) for the government to be Ricardian the government primary surplus should react positively to lagged debt; this can be tested for by checking the cointegration of revenue and spending with a unit coefficient. In the 'forward-looking' version due to Canzoneri et al. (2001), the future level of debt should react negatively to the current primary surplus. Here the test is of the impulse response function of debt to the surplus, but Bajo-Robio et al. point out that if a primary surplus today causes a lower primary surplus tomorrow the test would not hold. This version too requires cointegration to hold.

The cointegration test needs in principle to include inflation-tax revenues. But these revenues include the reduction in value of the debt due to inflation which are precisely those generated by FTPL to ensure solvency. As solvency is always assured in equilibrium in either Ricardian or FTPL conditions, so cointegration must hold in either condition; and

\footnotetext{
1 See for example Sims (1997); Woodford (1998b); Bergin (2000); Canzoneri et al. (2001), and Bajo-Rubio et al. (2009).

2 See Mèlitz (2000); Afonso (2000); Ballabriga and Martinez-Mongay (2003) and BajoRubio et al. (2014).
}

so, while interpretation is possible, there is strictly speaking no way of distinguishing which condition is causing this to happen.

As a result of this critique, some authors - for example Bianchi (2012); Bianchi and Melosi (2013) - have abandoned the idea of testing whether the FTPL was or was not prevailing in an episode. Instead they have assumed that various possible combinations of fiscal and monetary policy were operating at different times, with switching between them occurring according to some Markov process. They have then estimated, usually by Bayesian methods, what combinations were operating and when. In the context of the US, to which most of this work is devoted and where the constitution divides power between three branches of government, this idea that at any one time there is not necessarily a definite 'regime' operating but rather a constant process of flux between transitory regimes may well seem plausible. However, our paper investigates a specific episode in UK history; and the UK is a unitary state where there is no separation of executive powers and where an elected government is - until the next election - the sole setter of policy. Our brief description of the history of the 1970s above suggests that during this period FTPL may well have been the sole operating regime; it is the aim of this paper to test this hypothesis in a convincing way. The episode gives us the unusual opportunity to do this. If we could succeed in this objective, we would have answered an important empirical question: could FTPL ever have actually happened and therefore is it more than a theoretical curiosum?

We meet the identification critique head on in this paper by setting up specific versions of both the two models, FTPL and Orthodox, and testing each against the data. We first establish that, even though these two models may produce similar reduced forms, they are identifiable by the detailed differences within these reduced forms and cannot therefore be confused wth each other. Secondly, we follow a comprehensive testing procedure; we use Bayesian estimation, and rank the two models using various priors. We find that we cannot unambiguously rank these models regardless of the priors we use. We also try to rank them using the widely-used Likelihood Ratio test, using flat priors; but these rankings are unstable, apparently reflecting a rather flat likelihood function. Our principal test is to examine the models' ability to reproduce the data behaviour, which can be represented by impulse response functions or moments and cross-moments but which we represent parsimoniously here by the features of a VECM; this is the little-known method of 'indirect inference', whose power is high as a test, even in the rather small sample we have here.

Thus the contribution of this paper is to use full information econometric methods to test two rival structural models of the economy, one according to the FTPL approach and one according to the Orthodox

Table 2

Identification check: FTPL vs Orthodox Taylor.

\begin{tabular}{ll}
\hline When the true model is & $\begin{array}{l}\text { Rejection rate (at 95\% confidence level) } \\
\text { of the false model }\end{array}$ \\
\hline FTPL & $24.5 \%$ (Orthodox) \\
Orthodox & $22.2 \%$ (FTPL) \\
\hline
\end{tabular}



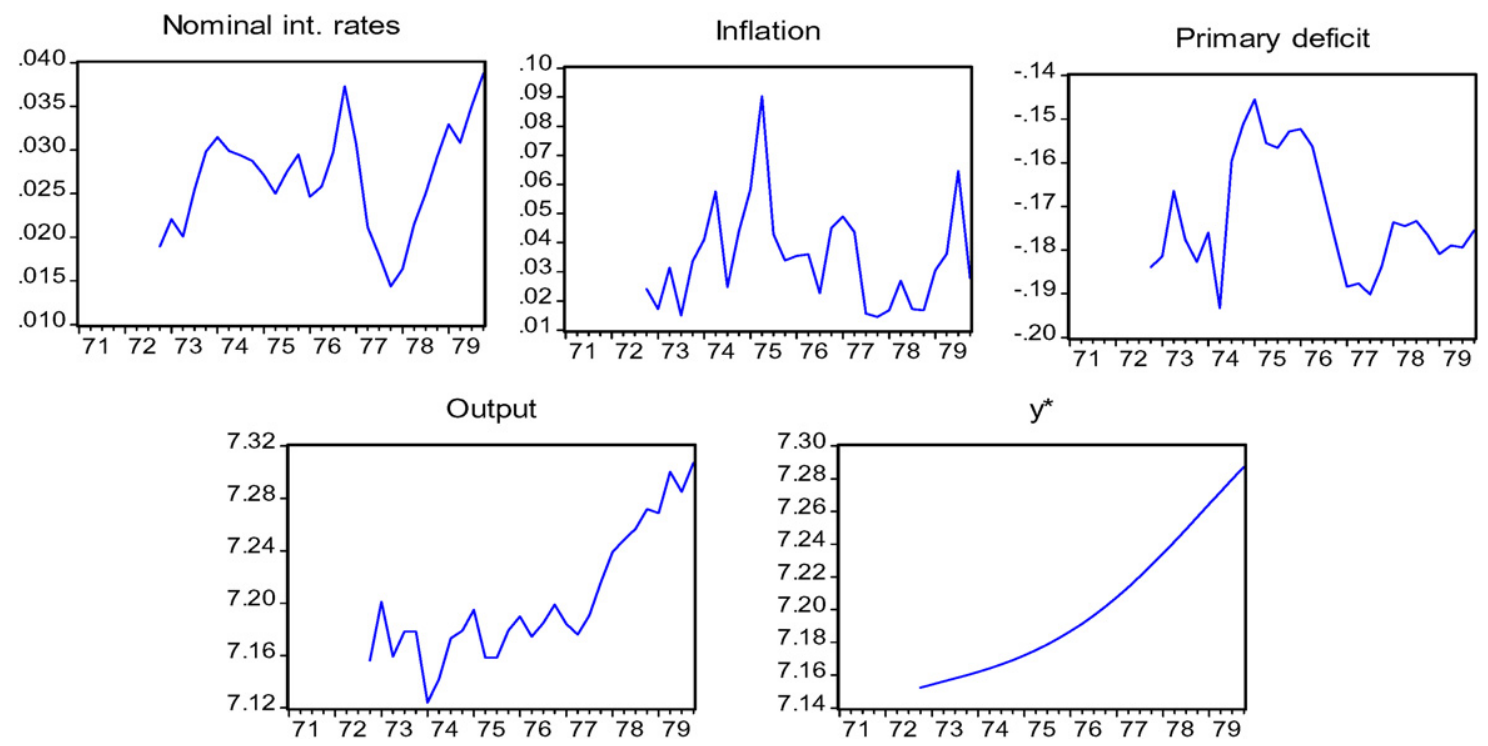

Fig. 1. UK Data (1972-1979).

approach, for the behaviour of the UK economy during the 1970s and 1980s.

To anticipate our findings, we cannot reject either hypothesis for the 1970s; however we show that we can create a combination of the two models which greatly dominates either model on its own but still gives an important role to fiscal policy in determining inflation in this period. For the 1980s the same combination model again improves substantially on the individual models (which again cannot be individually rejected) and gives a continued, though much diminished, role to fiscal policy. These results make sense of the important position that fiscal policy occupied in the UK inflation debates during these two decades.

Our paper is organised as follows. We review the history of UK policy during the 1970s in Section 2; in this section we establish a narrative that suggests the FTPL could have been at work. In Section 3 we set up a particular model of FTPL that we argue could be a candidate to explain this UK episode; side by side with it we set out a particular rival 'Orthodox' model in which monetary policy is governed by a Taylor Rule and fiscal policy is Ricardian. In Section 4 we discuss the data and the results of our testing procedure. In Section 5 we compare our results with those for the 1980s. Section 6 concludes.

Table 3

Indirect estimates of the FTPL and the Orthodox models.

\begin{tabular}{|c|c|c|c|}
\hline Model parameter & Starting value & FTPL & Orthodox Taylor \\
\hline$\theta$ & 2.4 & 4.07 & 1.96 \\
\hline$\beta$ & 0.99 & fixed & fixed \\
\hline$\sigma$ & 2.27 & 0.02 & 0.46 \\
\hline$\kappa$ & 0.26 & 0.35 & - \\
\hline$\rho$ & 0.5 & - & 0.76 \\
\hline$\phi_{\pi}$ & 2 & - & 1.31 \\
\hline$\phi_{\text {xgap }}$ & 0.125 & - & 0.06 \\
\hline$\delta$ & 0.003 & - & 0.007 \\
\hline$c^{y^{*}}$ & 0.0002 & fixed & fixed \\
\hline$\gamma$ & 0.99 & fixed & fixed \\
\hline \multicolumn{4}{|c|}{ Shock persistence (rho's) } \\
\hline$e r r^{p p}$ & - & 0.43 & 0.42 \\
\hline$e r r^{I S}$ & - & 0.64 & 0.84 \\
\hline$e r r^{y^{*}}$ & - & 0.93 & 0.93 \\
\hline$e r r^{g-t}$ & - & -0.1 & -0.1 \\
\hline$e r r^{\pi}$ & - & 0.24 & - \\
\hline$e r r^{R^{S}}$ & - & - & 0.33 \\
\hline
\end{tabular}

\section{The nature of UK policy during the 1970s}

From WWII until its breakdown in 1970 the Bretton Woods system governed the UK exchange rate and hence its monetary policy. While exchange controls gave some moderate freedom to manage interest rates away from foreign rates without the policy being overwhelmed by capital movements, such freedom was mainly only for the short term; the setting of interest rates was dominated in the longer term by the need to control the balance of payments sufficiently to hold the sterling exchange rate. Pegging the exchange rate implied that the price level was also pegged to the foreign price level. Through this mechanism monetary policy ensured price level determinacy. Fiscal policy was therefore disciplined by the inability to shift the price level from this trajectory and also by the consequent fixing of the home interest rate to the foreign level. While this discipline could in principle be overthrown by fiscal policy forcing a series of devaluations, the evidence suggests that this did not happen; there were just two devaluations during the whole post-war period up to 1970, in 1949 and 1967. On both occasions a Labour government viewed the devaluation as a one-off change permitting a brief period of monetary and fiscal ease, to be followed by a return to the previous regime.

However, after the collapse of Bretton Woods, the UK moved in a series of steps to a floating exchange rate. Initially sterling was fixed to continental currencies through a European exchange rate system known as 'the snake in the tunnel', designed to hold rates within a general range (the tunnel) and if possible even closer (the snake). Sterling proved difficult to keep within these ranges, and was in practice kept

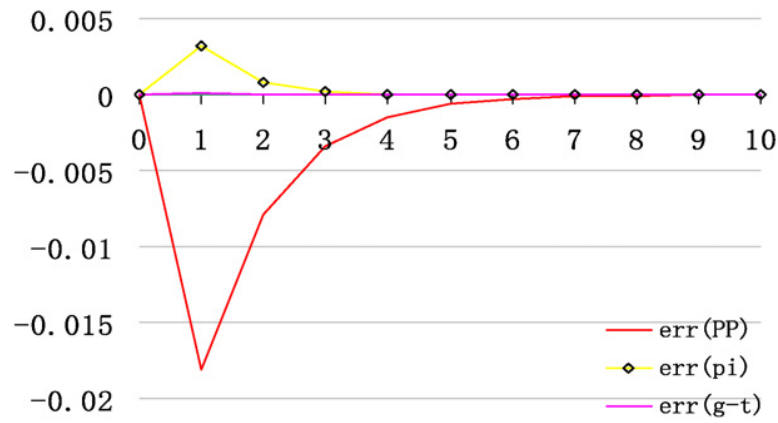

Fig. 2. IRFs - Output (FTPL). 


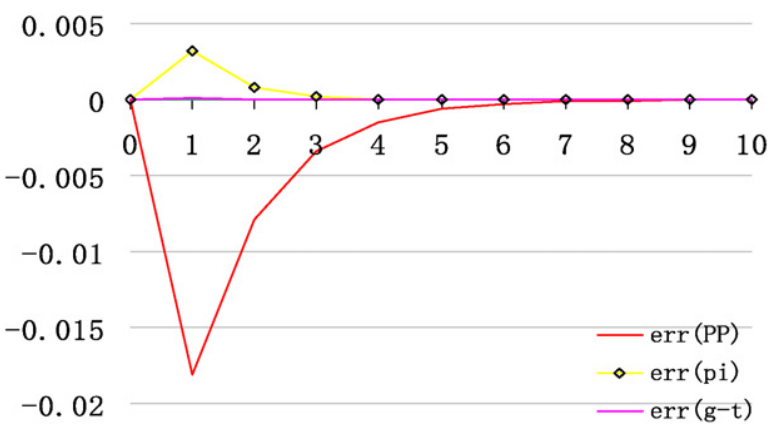

Fig. 3. IRFs - Inflation (FTPL).

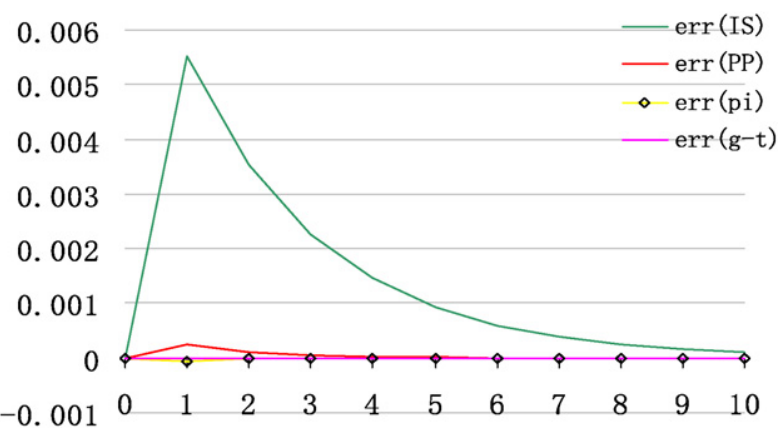

Fig. 5. IRFs - Real int. rates (FTPL). within a range against the dollar at an 'effective' (currency basket) rate. Finally it was formally floated in June 1972.

UK monetary policy was not given a new nominal target to replace the exchange rate. Instead the Conservative government of Edward Heath assigned the determination of inflation to wage and price controls. A statutory 'incomes policy' was introduced in late 1972. After the 1974 election the incoming Labour government set up a 'voluntary incomes policy', buttressed by food subsidies and cuts in indirect tax rates. Fiscal policy was expansionary until 1975 and monetary policy was accommodative, with interest rates kept low to encourage falling unemployment. In 1976 the Labour government invited the IMF to stabilise the falling sterling exchange rate; the IMF terms included the setting of targets for Domestic Credit Expansion. These were largely met by a form of control on deposits ( the 'corset') which forced banks to reduce deposits in favour of other forms of liability. But by 1978 these restraints had effectively been abandoned and prices and incomes controls reinstated in the context of a pre-election fiscal and monetary expansion see Minford (1993); Nelson (2003) and Meenagh et al. (2009b) for further discussions of the UK policy environment for this and other post-war UK periods.

Our description of policy suggests that the role of the nominal anchor for inflation may have been played during the 1970s by fiscal policy, if only because monetary policy was not given this task and was purely accommodative. Thus this episode appears on the face of it to be a good candidate for FTPL to apply.

\section{An FTPL Model for the UK in the 1970s}

In what follows we set out a simple particular model of the FTPL that captures key aspects of UK behaviour. The model is a New Keynesian model as set out in Clarida et al. (1999): there is a labour-only production function among firms supplying intermediate goods under imperfect competition and Calvo pricing, retail bundlers turn these goods into final products under perfect competition, households have utility over consumption and leisure and all agents have rational expectations. This standard set-up is used because it is empirically successful (e.g. Liu and Minford, 2014) and enables us to focus our attention on the role of

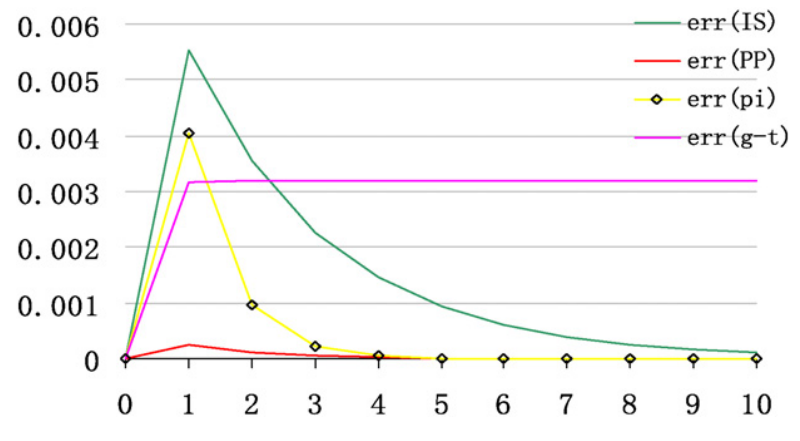

Fig. 4. IRFs - Nom. int. rates (FTPL). government behaviour. The UK is an open economy but during all our sample period it floated the pound and this is well-known to generate behaviour close to that of a closed economy. We now turn to the government budget constraint and fiscal policy under FTPL. In the next section we will outline the alternative Ricardian model.

We assume that the UK finances its deficit by issuing nominal perpetuities, each paying one pound per period and whose present value is therefore $\frac{1}{R_{t}}$ where $R_{t}$ is the long-term rate of interest. We use perpetuities here rather than the usual one-period bond because of the preponderance of long-term bonds in the UK debt issue: the average maturity of UK debt at this time was approximately ten years but a model with a realistic maturity structure would lose tractability. All bonds at this time were nominal (indexed bonds were not issued until 1981).

The government budget constraint can then be written as:

$\frac{B_{t+1}}{R_{t}}=G_{t}-T_{t}+B_{t}+\frac{B_{t}}{R_{t}}$

where $G_{t}$ is government spending in money terms, $T_{t}$ is government taxation in money terms, $B_{t}$ is the number of perpetuities issued. Note that when perpetuities are assumed the debt interest in period $t$ is $B_{t}$ while the stock of debt at the start of period $t$ has the value during the period of $\frac{B_{t}}{R_{t}}$; end-period debt therefore has the value $\frac{B_{t+1}}{R_{t}}$. Note too the perpetuity interest rate is by construction expected to remain constant into the future.

We can derive the implied value of current bonds outstanding by substituting forwards for future bonds outstanding:

$\frac{B_{t}}{R_{t}}=E_{t} \sum_{i=0}^{\infty}\left(T_{t+i}-G_{t+i}\right) \frac{1}{\left(1+R_{t}\right)^{i+1}}$

We now define each period's expected 'permanent' tax and spending share, $\bar{t}_{t}$ and $\bar{g}_{t}$, such that $\sum_{i=0}^{\infty} E_{t} T_{t+i} \frac{1}{\left(1+R_{t}\right)^{i+1}}=\bar{t}_{t} \sum_{i=0}^{\infty} E_{t} P_{t+i} y_{t+i}$ $\frac{1}{\left(1+R_{t}\right)^{i+1}}$ and $\sum_{i=0}^{\infty} E_{t} G_{t+i} \frac{1}{\left(1+R_{t}\right)^{i+1}}=\bar{g}_{t} \sum_{i=0}^{\infty} E_{t} P_{t+i} y_{t+i} \frac{1}{\left(1+R_{t}\right)^{i+1}}$. Thus these two shares summarise the key fiscal settings, in the same way that a consumer's permanent income replaces the consumer's complex income prospects with a constant stream of income with the same present value. It is a feature of such permanent variables (a class to which the perpetuity interest rate also belongs since it is the expected average

Table 4

Variance decomposition (FTPL)

\begin{tabular}{lcccc}
\hline Unit: $\%$ & $\mathrm{y}$ & $\pi$ & $R^{S}$ & $\mathrm{r}$ \\
\hline$e r r^{I S}:$ & 0 & 0 & 23.1 & 99.9 \\
$e r r^{P P}:$ & 79.1 & 0 & 0 & 0.1 \\
$e r r^{\pi}:$ & 2.2 & 67.1 & 8 & 0 \\
$e r r^{y^{*}}:$ & 18.7 & 0 & 0 & 0 \\
$e r r^{g-t}:$ & 0 & 32.9 & 68.9 & 0 \\
Total: & 100 & 100 & 100 & 100 \\
\hline
\end{tabular}




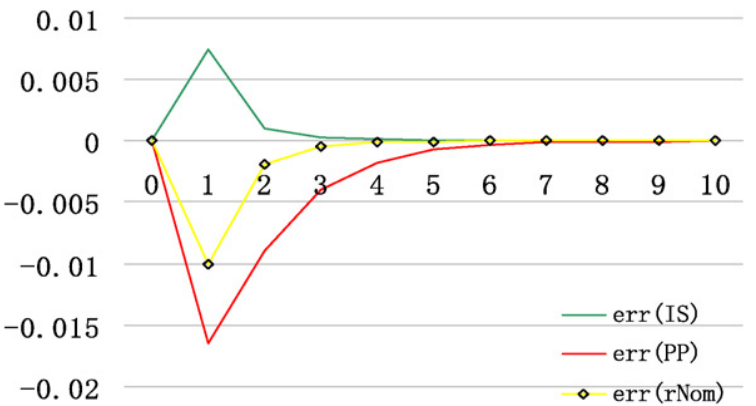

Fig. 6. IRFs - Output (Orthodox Taylor)

of all future one-period interest rates) that they follow a random walkHall (1978). We will exploit this feature in what follows, both to develop a parsimonious version of this model's behaviour and to distinguish this model from the Orthodox model.

(2) becomes:

$\frac{B_{t}}{R_{t}}=\left(\bar{t}_{t}-\bar{g}_{t}\right) \sum_{i=0}^{\infty} E_{t} P_{t+i} y_{t+i} \frac{1}{\left(1+R_{t}\right)^{i+1}}$

Now define $\bar{\pi}_{t}, \bar{\gamma}_{t}$ as the expected permanent growth rates of $\bar{P}_{t}, y_{t}^{*}$, respectively the equilibrium or 'trend' price and output levels, such that.

$\sum_{i=0}^{\infty} E_{t} P_{t+i} y_{t+i} \frac{1}{\left(1+R_{t}\right)^{i+1}}=\bar{P}_{t} y_{t}^{*} \sum_{i=0}^{\infty} \frac{\left(1+\bar{\gamma}_{t}+\bar{\pi}_{t}\right)^{i}}{\left(1+R_{t}\right)^{1+i}}$

Note that if $\bar{\gamma}_{t}$ and $\bar{\pi}_{t}$ are both small enough and because by the Fisher equation we can define the riskless real perpetuities interest rate as $r_{t}^{*}=$ $R_{t}-\bar{\pi}_{t}$, we can rewrite:

$$
\begin{aligned}
\sum_{i=0}^{\infty} \frac{\left(1+\bar{\gamma}_{t}+\bar{\pi}_{t}\right)^{1+i}}{\left(1+R_{t}\right)^{1+i}} & =\sum_{i=0}^{\infty}\left(\frac{1}{1+R_{t}-\bar{\gamma}_{t}-\bar{\pi}_{t}}\right)^{1+i} \\
& =\left(\frac{1}{1-\frac{1}{1+r_{t}^{*}-\bar{\gamma}_{t}}}-1\right)=\left(\frac{1}{r_{t}^{*}-\bar{\gamma}_{t}}\right)
\end{aligned}
$$

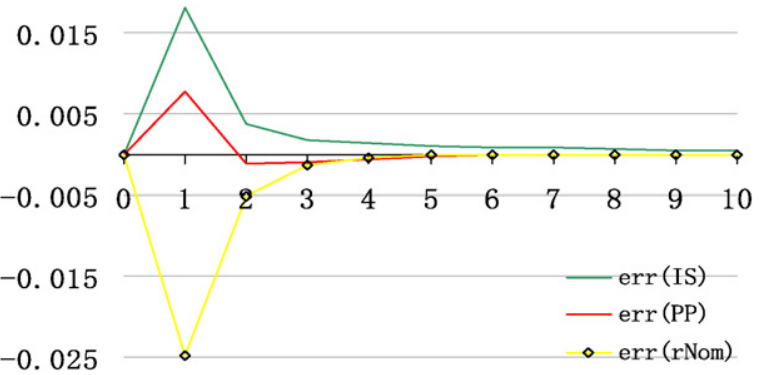

Fig. 7. IRFs - Inflation (Orthodox Taylor)

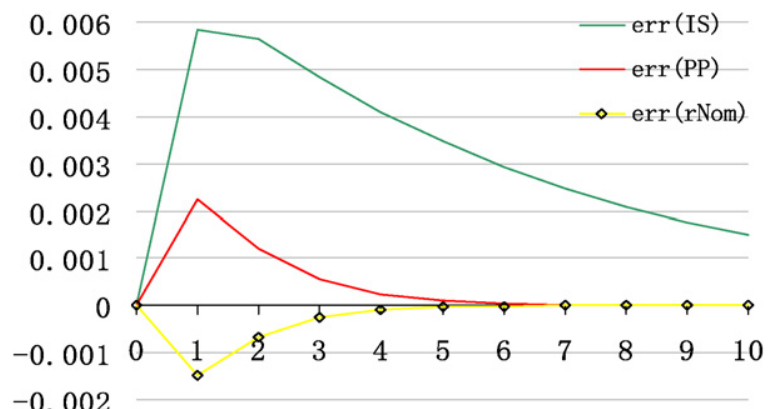

Fig. 8. IRFs - Nom. int. rates (Orthodox Taylor).

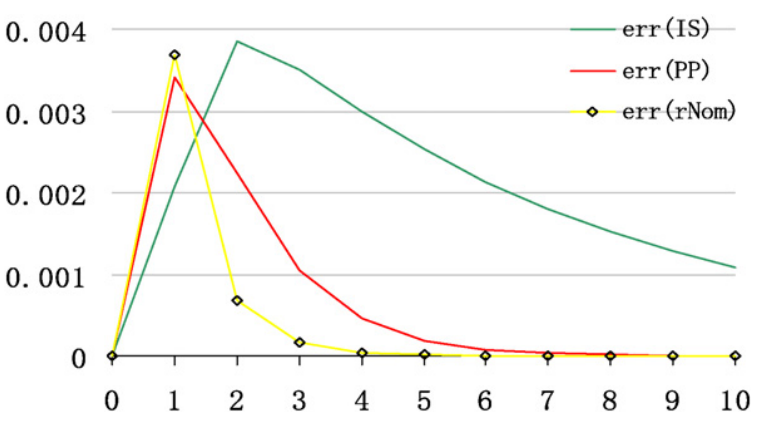

Fig. 9. IRFs - Real int. rates (Orthodox Taylor).

Hence (2) now can be rewritten as:

$\frac{B_{t}}{R_{t} \bar{P}_{t} y_{t}^{*}}=\frac{\left(\bar{t}_{t}-\bar{g}_{t}\right)}{\left(1+\bar{\gamma}_{t}+\bar{\pi}_{t}\right)\left(r_{t}^{*}-\bar{\gamma}_{t}\right)}$

The pricing condition on bonds in Eq. (3) thus sets their value consistently with expected future primary surpluses. Suppose now the government reduces the present value of future primary surpluses. At an unchanged real value of the debt this would be a 'non-Ricardian' fiscal policy move. According to the FTPL prices will adjust to reduce the real value of the debt to ensure that the solvency condition is met. This is to be compared with the normal Ricardian situation, in which fiscal surpluses are endogenous so that fiscal shocks today lead to adjustments in future surpluses, the price level remaining unaffected.

Since the pricing equation sets the ratio of debt value to GDP equal to a function of permanent variables, it follows that this ratio $b_{t}$ follows a random walk ${ }^{3}$ such that:

$b_{t}=\frac{B_{t}}{R_{t} \bar{P}_{t} y_{t}^{*}}=E_{t} b_{t+1}$

and

$\Delta b_{t}=\eta_{t}$

which is an i.i.d.process

This in turn allows us to solve for the inflation shock as a function of other shocks (especially shocks to government tax and spending). With the number of government bonds issued, $B_{t}$, being pre-determined (issued last period) and therefore known at $t-1$, Eq. (3) could be written as follows (taking $\log$ and letting $\log x_{t}^{u e}=\log x_{t}-E_{t-1} \log x_{t}$, the unexpected change in $\left.\log x_{t}\right)$ :

$$
\begin{aligned}
\log b_{t}^{u e}=- & \log R_{t}^{u e}-\log \bar{P}_{t}^{u e}-\log y_{t}^{* u e} \quad[\text { LHS of equation (3)] } \\
= & \log \left(\bar{t}_{t}-\bar{g}_{t}\right)^{u e}-\log \left(1+\bar{\pi}_{t}+\bar{\gamma}_{t}\right)^{u e} \\
& -\log \left(r_{t}^{*}-\bar{\gamma}_{t}\right)^{u e} \quad[\text { RHS of equation (3)] }
\end{aligned}
$$

In considering empirically how these unanticipated terms should be evaluated, we first note that the expected underlying growth rate will be estimated as a function of the drift term (the constant) in the estimated equation for $\Delta \log y_{t}^{*}$ (as exemplified below in our empirical section where it is found to be best treated as an I(1) variable Eq. (15) below); hence we assume it will not change from period to period in this short sample of less than a decade and so treat $\bar{\gamma}_{t}=\gamma$, a constant. With all the variables in the equation defined to follow a random walk (or in the case of $y_{t}^{*}$ an $\mathrm{I}(1)$ process of the form $\left.\Delta \log y_{t}^{*}=\gamma \Delta \log y_{t-1}{ }^{*}+c^{y^{*}}+e r r_{t}^{y^{*}}\right)$, and approximating unexpected changes in actual and permanent inflation as equal (so that for small

\footnotetext{
${ }^{3}$ A 'permanent' variable $\bar{x}_{t}$ is by definition a variable expected not to change in the future so that $E_{t} \bar{x}_{t+1}=\bar{x}_{t}$. Thus $\bar{x}_{t+1}=\bar{x}_{t}+\varepsilon_{t+1}$, where $\varepsilon_{t+1}$ is an iid error making the process a random walk.
} 
Table 5

Variance decomposition (Orthodox Taylor).

\begin{tabular}{|c|c|c|c|c|}
\hline Unit: \% & $\mathrm{y}$ & $\pi$ & $R^{S}$ & $\mathrm{r}$ \\
\hline errIS: & 8.9 & 33.3 & 93.2 & 62.8 \\
\hline $\operatorname{err}^{P P}:$ & 58.8 & 6.1 & 4.9 & 20.8 \\
\hline$e r r^{R^{s}}:$ & 16.8 & 60.1 & 1.9 & 16.3 \\
\hline$e r r^{y^{*}}:$ & 15.5 & 0 & 0 & 0 \\
\hline$e r r^{g-t}$ & 0 & 0 & 0 & 0 \\
\hline Total: & 100 & 100 & 100 & 100 \\
\hline
\end{tabular}

$\left.\gamma, \log \left(1+\bar{\pi}_{t}+\gamma\right)^{u e} \approx \bar{\pi}_{t}^{u e} \simeq \log \bar{P}_{t}^{u e}\right)$, we can rewrite the above expression as approximately:

$-\Delta \log \left(\bar{\pi}_{t}+r_{t}^{*}\right)-\left(\Delta \log y_{t}^{*}-\gamma \Delta \log y_{t-1}^{*}-c^{y *}\right)=\Delta \log \left(\bar{t}_{t}-\bar{g}_{t}\right)-\Delta \log \left(r_{t}^{*}-\gamma\right)(7)$

Using a first-order Taylor Series expansion around the sample means we can obtain a solution for $\Delta \bar{\pi}_{t}$ as a function of change in government expenditure and tax rates:

$\Delta \bar{\pi}_{t}=\kappa\left(\Delta \bar{g}_{t}-\Delta \bar{t}_{t}\right)+\lambda \Delta r_{t}^{*}-\mu \Delta(1-\gamma L) \log y_{t}^{*}$

where $\kappa=\frac{\overline{\bar{\pi}}+\overline{r^{*}}}{\bar{t}-\overline{\bar{g}}}, \lambda=\frac{\overline{\bar{\pi}}+\gamma}{r^{*}-\gamma}, \mu=\overline{\bar{\pi}}+\overline{r^{*}} ; \overline{\bar{\pi}}, \overline{r^{*}}, \overline{\bar{t}}$ and $\overline{\bar{g}}$ are sample mean values of the corresponding variables. We can integrate (8) to obtain:

$\bar{\pi}_{t}=\kappa\left(\bar{g}_{t}-\bar{t}_{t}\right)+c+\lambda r_{t}^{*}+\mu(1-\gamma \mathrm{L}) \log y_{t}^{*}$
Table 7

Wald tests of the FTPL and the Orthodox models.

\begin{tabular}{lrl}
\hline Elements tested & \multicolumn{1}{l}{ FTPL } & Orthodox \\
\hline Dynamics (VARX coeff. only) & $77.4(0.226)$ & $78.1(0.219)$ \\
Volatility (VARX resid. only) & $6.9(0.931)$ & $59.3(0.407)$ \\
All elements (VARX coeff. + resid.) & $69.3(0.307)$ & $84.9(0.151)$ \\
\hline
\end{tabular}

Note: $p$-values in parentheses; $p$-value $=(100-$ Wald percentile $) / 100$.

Table 8

Marginal log data likelihood with strong priors.

\begin{tabular}{llll}
\hline Selected prior type & FTPL model & Orthodox model & Dominant model \\
\hline FTPL prior & 481.8486 & 467.4937 & FTPL \\
Orthodox prior & 431.16 & 449.3487 & Orthodox \\
\hline
\end{tabular}

Note: the marginal data likelihoods are calculated using the Laplace Approximation estimator.

Tax and spending ratios are assumed to deviate temporarily from their permanent values according to error processes (which must be stationary by construction). Thus:

$\left(g_{t}-t_{t}\right)=\left(\bar{g}_{t}-\bar{t}_{t}\right)+\varepsilon_{t}$

Since by construction a permanent variable follows a random walk, this gives us:

$\Delta\left(g_{t}-t_{t}\right)=\Delta\left(\bar{g}_{t}-\bar{t}_{t}\right)+\Delta \varepsilon_{t}=\operatorname{err}_{t}^{g-t}$

where $e r r_{t}^{g-t}$ is a stationary error process. We may now note that there is some unknown error process by which actual inflation is related to

Table 6

VECM estimates: actual vs model simulations.

\begin{tabular}{|c|c|c|c|c|c|}
\hline $\begin{array}{l}\text { VARX } \\
\text { parameter }\end{array}$ & Actual & FTPL lower & FTPL upper & $\begin{array}{l}\text { Ortho. } \\
\text { lower }\end{array}$ & $\begin{array}{l}\text { Ortho. } \\
\text { upper }\end{array}$ \\
\hline \multicolumn{6}{|l|}{$y_{t}$ on } \\
\hline$y_{t-1}$ & -0.2740 & -0.2835 & 0.6075 & -0.2551 & $0.6552^{\mathrm{a}}$ \\
\hline$\pi_{t-1}$ & -0.3808 & -0.6171 & 0.4412 & -0.6558 & 0.3253 \\
\hline$R_{t-1}^{S}$ & -0.3502 & -1.9803 & 1.5485 & -2.3809 & 1.0812 \\
\hline$(g-t)_{t-1}$ & 0.7864 & -1.1111 & 0.8224 & -1.0967 & 0.8337 \\
\hline$y_{t-1}$ & 3.2576 & -2.8302 & 4.1978 & -3.0749 & 4.0808 \\
\hline Trend & -0.0089 & -0.0069 & $0.0083^{\mathrm{a}}$ & -0.0079 & $0.0074^{*}$ \\
\hline \multicolumn{6}{|l|}{$\pi_{t}$ on } \\
\hline$y_{t-1}$ & 0.3353 & -0.5080 & 0.4997 & -0.3631 & 0.6922 \\
\hline$\pi_{t-1}$ & 0.3231 & -0.4205 & 0.4611 & -0.4481 & 0.3925 \\
\hline$R_{t-1}^{s}$ & 1.4273 & -1.0472 & 2.2328 & -0.8633 & 2.5227 \\
\hline$(g-t)_{t-1}$ & 0.2311 & -0.5509 & 1.3441 & -0.7512 & 1.1868 \\
\hline$y_{t-1}$ & -0.5633 & -2.7752 & 3.6702 & -3.4731 & 3.1963 \\
\hline Trend & 0.0011 & -0.0072 & 0.0074 & -0.0075 & 0.0069 \\
\hline \multicolumn{6}{|l|}{$R_{t}^{s}$ on } \\
\hline$y_{t-1}$ & -0.0400 & -0.1318 & 0.1130 & -0.0591 & 0.1801 \\
\hline$\pi_{t-1}$ & -0.0424 & -0.2102 & 0.0395 & -0.1588 & 0.0612 \\
\hline$R_{t-1}^{s}$ & 0.7967 & -0.0015 & $0.7624^{*}$ & -0.2494 & 0.9357 \\
\hline$(g-t)_{t-1}$ & 0.1672 & -0.0162 & 0.4026 & -0.2041 & 0.2378 \\
\hline$y_{t-1}$ & 0.3204 & -0.8594 & 0.9805 & -0.8656 & 0.7144 \\
\hline Trend & -0.0012 & -0.0016 & 0.0019 & -0.0024 & 0.0011 \\
\hline \multicolumn{6}{|l|}{$(g-t)_{t}$ on } \\
\hline$y_{t-1}$ & 0.2262 & -0.2832 & 0.3034 & -0.3041 & 0.3116 \\
\hline$\pi_{t-1}$ & 0.1545 & -0.3164 & 0.2820 & -0.2908 & 0.2658 \\
\hline$R_{t-1}^{s}$ & -0.3739 & -1.0098 & 0.9486 & -1.1319 & 1.0838 \\
\hline$(g-t)_{t-1}$ & 0.4939 & -0.0605 & 0.8618 & -0.1124 & 0.8305 \\
\hline$y_{t-1}$ & -0.6407 & -2.9531 & 2.7573 & -3.2408 & 2.5242 \\
\hline Trend & 0.0017 & -0.0057 & 0.0063 & -0.0062 & 0.0077 \\
\hline $\operatorname{Var}\left(\operatorname{resid}^{y}\right)$ & $1.80 \times 10^{-4}$ & $0.85 \times 10^{-4}$ & $3.18 \times 10^{-4}$ & $0.74 \times 10^{-4}$ & $3.09 \times 10^{-4}$ \\
\hline $\operatorname{Var}\left(\operatorname{resid}^{\pi}\right)$ & $1.27 \times 10^{-4}$ & $0.70 \times 10^{-4}$ & $2.85 \times 10^{-4}$ & $0.59 \times 10^{-4}$ & $2.89 \times 10^{-4}$ \\
\hline $\operatorname{Var}\left(\operatorname{resid}^{R^{S}}\right)$ & $0.10 \times 10^{-4}$ & $0.05 \times 10^{-4}$ & $0.15 \times 10^{-4}$ & $0.04 \times 10^{-4}$ & $0.13 \times 10^{-4}$ \\
\hline $\operatorname{Var}\left(\right.$ resid $\left.^{g-t}\right)$ & $0.68 \times 10^{-4}$ & $0.18 \times 10^{-4}$ & $1.11 \times 10^{-4}$ & $0.17 \times 10^{-4}$ & $1.15 \times 10^{-4}$ \\
\hline
\end{tabular}

\footnotetext{
a Number lying beyond the lower/upper bound.
} 
Table 9

Comparing the FIML and II estimates.

\begin{tabular}{|c|c|c|c|c|}
\hline & FTPL model & $\begin{array}{l}\text { Orthodox } \\
\text { model }\end{array}$ & & \\
\hline Model parameter & ML estimates & II estimates & $\begin{array}{l}\text { ML } \\
\text { estimates }\end{array}$ & $\begin{array}{l}\text { II } \\
\text { estimates }\end{array}$ \\
\hline$\theta$ & 2.42 & 4.07 & 2.38 & 1.96 \\
\hline$\beta$ & Fixed at 0.99 & Fixed at 0.99 & & \\
\hline$\sigma$ & 2.13 & 0.02 & 2.22 & 0.46 \\
\hline$\kappa$ & 0.17 & 0.35 & - & - \\
\hline$\rho$ & - & - & 0.84 & 0.76 \\
\hline$\phi_{\pi}$ & - & - & 1.97 & 1.31 \\
\hline$\phi_{\text {xgap }}$ & - & - & 0.19 & 0.06 \\
\hline$\delta$ & - & - & 0.22 & 0.007 \\
\hline$c^{y^{*}}$ & $\begin{array}{l}\text { Fixed at } \\
0.0002\end{array}$ & $\begin{array}{l}\text { Fixed at } \\
0.0002\end{array}$ & & \\
\hline$\gamma$ & Fixed at 0.99 & Fixed at 0.99 & & \\
\hline \multicolumn{5}{|c|}{ Shock persistence (rho's) } \\
\hline$e r r^{p p}$ & 0.96 & 0.43 & 0.51 & 0.42 \\
\hline$e r r^{I S}$ & 0.51 & 0.64 & 0.39 & 0.84 \\
\hline$e r r^{y^{*}}$ & 0.97 & 0.93 & 0.97 & 0.93 \\
\hline$e r r^{g-t}$ & -0.1 & -0.1 & -0.05 & -0.1 \\
\hline$e r r^{\pi}$ & 0.36 & 0.24 & - & - \\
\hline$e r r^{R^{S}}$ & - & - & 0.31 & 0.33 \\
\hline $\begin{array}{l}\text { LR percentile } \\
\text { ( } p \text {-value) }\end{array}$ & $\begin{array}{l}40.8 \\
(0.592)\end{array}$ & $\begin{array}{l}75.5 \\
(0.245)\end{array}$ & $\begin{array}{l}76.6 \\
(0.234)\end{array}$ & $\begin{array}{l}74.4 \\
(0.256)\end{array}$ \\
\hline $\begin{array}{l}\text { Full Wald } \\
\text { percentile }\end{array}$ & 94.5 & 69.3 & 95.4 & 84.9 \\
\hline ( $p$-value) & $(0.055)$ & $(0.307)$ & $(0.046)$ & $(0.151)$ \\
\hline
\end{tabular}

Note: $p$-values in parentheses; $p$-value $=(100$-reported percentile $) / 100$.

permanent inflation: thus $\pi_{t}=\bar{\pi}_{t}+\eta_{t}$. We use (9) for the determinants of $\bar{\pi}_{t}$ and since we cannot observe $\left(\lambda r_{t}^{*}+\mu(1-\gamma L) \log y_{t}^{*}\right)$ we include this in the total error process, $\operatorname{err}_{t}^{p i}$, so that finally our FTPL model for inflation is:

$\pi_{t}=\kappa\left(g_{t}-t_{t}\right)+c^{\pi}+e r r_{t}^{p i}$

We can now complete the DSGE model by adding a forward-looking IS curve, derived in the usual way from the household Euler equation and the goods market-clearing condition, and a New Keynesian Phillips Curve (following Clarida et al. (1999) as noted earlier):

$y_{t}-y_{t}^{*}=E_{t}\left(y_{t+1}-y_{t+1}^{*}\right)-\frac{1}{\sigma}\left(R_{t}^{S}-E_{t} \pi_{t+1}\right)+e r r_{t}^{I S}$

Table 10

Indirect estimates of the models: Weighted vs FTPL and Orthodox.

\begin{tabular}{|c|c|c|c|}
\hline Model parameter & FTPL & Orthodox Taylor & Weighted model \\
\hline$\theta$ & 4.07 & 1.96 & 0.05 \\
\hline$\beta$ & \multicolumn{3}{|c|}{----fixed at $0.99----$} \\
\hline$\sigma$ & 0.02 & 0.46 & 1.78 \\
\hline$\kappa$ & 0.35 & - & 0.81 \\
\hline$\rho$ & - & 0.76 & 0.78 \\
\hline$\phi_{\pi}$ & - & 1.31 & 1.84 \\
\hline$\phi_{\text {xgap }}$ & - & 0.06 & 0.22 \\
\hline$\delta$ & - & 0.007 & 0.01 \\
\hline$c^{y^{*}}$ & \multirow{2}{*}{\multicolumn{3}{|c|}{$\begin{array}{l}--- \text { fixed at } 0.0002---- \\
---- \text { fixed at } 0.99----\end{array}$}} \\
\hline$\gamma$ & & & \\
\hline Weight & - & - & 0.58 \\
\hline \multicolumn{4}{|c|}{ Shock persistence (rho's) } \\
\hline$e r r^{p p}$ & 0.43 & 0.42 & 0.29 \\
\hline $\mathrm{err}^{I S}$ & 0.64 & 0.84 & 0.58 \\
\hline$e r y^{y^{*}}$ & 0.93 & 0.93 & 0.95 \\
\hline$e r r^{g-t}$ & -0.1 & -0.1 & -0.1 \\
\hline$e r r^{\pi}$ & 0.24 & - & - \\
\hline$e r r^{R^{S}}$ & - & 0.33 & - \\
\hline errWeighted $\pi$ & - & - & 0.22 \\
\hline
\end{tabular}

Table 11

$P$-values of the models: Weighted vs FTPL and Orthodox.

\begin{tabular}{llll}
\hline Elements tested & FTPL & Orthodox & Weighted model \\
\hline Dynamics (VARX coeff. only) & 0.226 & 0.219 & 0.408 \\
Volatility (VARX resid. only) & 0.931 & 0.407 & 0.887 \\
All elements (VARX coeff. + resid.) & 0.307 & 0.151 & 0.562 \\
\hline Note: $p$-value $=(100-$ Wald percentile) $/ 100$. & & \\
& & \\
$\pi_{t}=\theta\left(y_{t}-y_{t}^{*}\right)+\beta E_{t} \pi_{t+1}+\operatorname{err}_{t}^{P P}$ & &
\end{tabular}

Note that the interest rate in the IS curve, $R_{t}^{s}$, is the usual short term rate. Also we can see that since (12) sets inflation, (14) will solve for output and (13) will solve for interest rates. Equilibrium output, $y_{t}^{*}$, is represented empirically by the Hodrick-Prescott trend in output and estimated as an I(1) process, as already noted:

$y_{t}^{*}-y_{t-1}^{*}=c^{y *}+\gamma\left(y_{t-1}^{*}-y_{t-2}^{*}\right)+e r r_{t}^{y *}$

Our candidate FTPL model thus consists of Eqs. (11)-(15), with all equation errors assumed to follow an $A R(1)$ process. Notice that while the central bank can be thought of as 'setting' the short-term interest rate, it must do so consistently with (13); it is in this sense that 'monetary policy' is endogenous. (12), which drives inflation, can be thought of as a financial market equilibrium condition; financial markets (including the exchange rate which is not explicitly in the model) react to future fiscal trends by forecasting inflation and moving asset prices in line. The model is silent on 'off-equilibrium' behaviour: theoretical critics have seized on this as a problem (e.g Buiter, 1999, 2002). But the model is not alone in such silence; for example in the standard open economy model of floating exchange rates the exchange rate jumps continuously to clear the foreign exchange market - an equilibrium condition - and it simply makes no sense to ask what offequilibrium behaviour would be. The same is true here.

\subsection{An Orthodox model}

In order to test the FTPL model we have set out above, we need to distinguish it clearly from an alternative 'orthodox' model, in which fiscal policy is Ricardian and monetary policy determines inflation. In this model we make no alteration in our assumptions about firms and households. We only alter the behaviour of government. Hence we jettison Eqs. (11) and (12) above, coming from the FTPL, in favour of a Taylor Rule for monetary policy, setting $R_{t}^{s}$ in response to inflation and the output gap, and a Ricardian fiscal equation that restores the deficit to some equilibrium level. Thus in place of these two equations we have:

$R_{t}^{S}=(1-\rho)\left[r^{s S}+\phi_{\pi} \pi_{t}+\phi_{\text {xgap }}\left(y_{t}-y_{t}^{*}\right)\right]+\rho R_{t-1}^{S}+e r r_{t}^{R^{S}}$

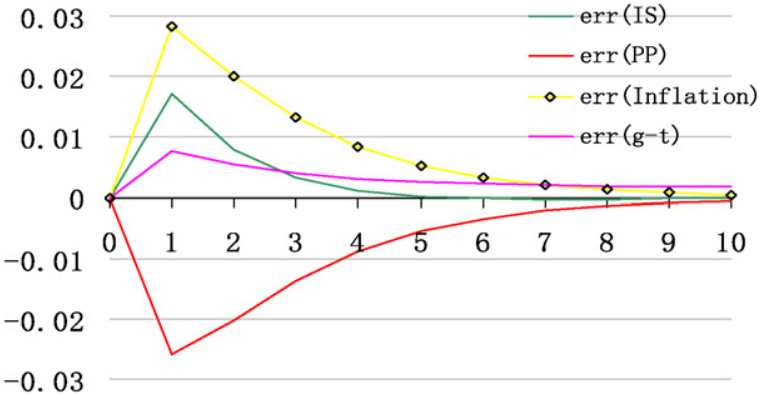

Fig. 10. IRFs - Output (Weighted model). 


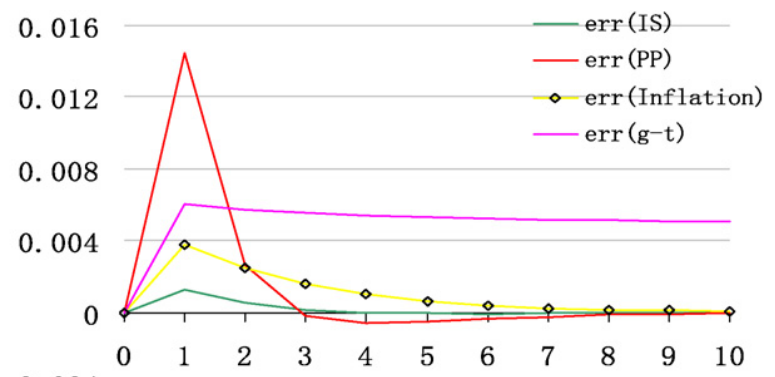

Fig. 11. IRFs - Inflation (Weighted model).

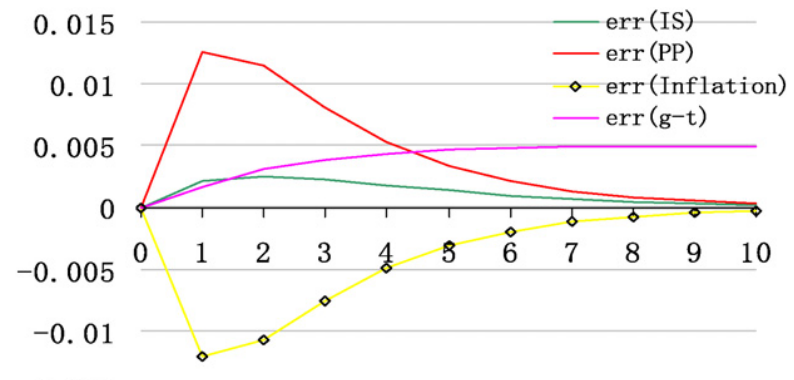

$-0.015$

Fig. 12. IRFs - Nom int. rates (Weighted model).

and

$\left.\Delta\left(g_{t}-t_{t}\right)=-\delta(g-t)_{t-1}-c^{g-t}\right]+e r r_{t}^{g-t^{\prime}}$

Notice that this last equation implies that the primary fiscal surplus is stationary; this in turn implies that its permanent value does not move (since if it did it would make the surplus non-stationary). We are to think of temporary variations in the surplus that do not alter long-run fiscal prospects. Thus in this model monetary policy sets inflation via a Taylor Rule and we assume that the fiscal surplus is set to ensure fiscal solvency given inflation, output and interest rates.

Table 1 summarizes the common and distinctive elements of the two models.

\subsection{The method of Indirect Inference}

The II method used here is that originally proposed in Meenagh et al. (2009a) and subsequently refined by Le et al. $(2011,2012)$ using Monte Carlo experiments. The approach employs an auxiliary model that is completely independent of the theoretical one to produce a description of the data against which the performance of the theory is evaluated indirectly. Such a description can be summarised either by the estimated

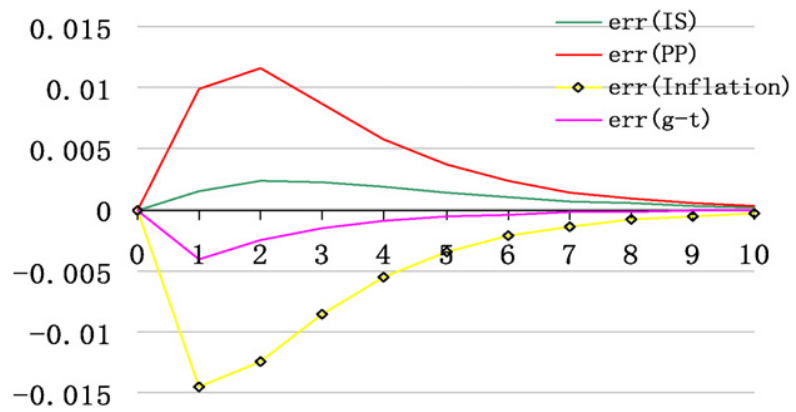

Fig. 13. IRFs - Real int. rates (Weighted model).
Table 12

Variance decomposition (weighted model).

\begin{tabular}{|c|c|c|c|c|}
\hline Unit: \% & $\mathrm{y}$ & $\pi$ & $R^{S}$ & $\mathrm{r}$ \\
\hline err ${ }^{I S}$ : & 10.8 & 0.3 & 2 & 2.2 \\
\hline$e r r^{P P}:$ & 39.3 & 34.3 & 37 & 40.2 \\
\hline errWeightedn: & 42.3 & 3.8 & 33.1 & 54.6 \\
\hline$e r r^{y^{*}}:$ & 3.4 & 0 & 0 & 0 \\
\hline$e r r^{g-t}$ : & 4.3 & 61.6 & 27.9 & 3 \\
\hline Total: & 100 & 100 & 100 & 100 \\
\hline
\end{tabular}

parameters of the auxiliary model or by functions of these; we will call these the descriptors of the data. While these are treated as the 'reality', the theoretical model being evaluated is simulated to find its implied values for them.

II has been widely used in the estimation of structural models (e.g., Smith, 1993; Gregory and Smith, 1991, 1993; Gourieroux et al., 1993; Gourieroux and Monfort, 1995 and Canova, 2005). Here we make a further use of it, to evaluate an already estimated or calibrated structural model. The common element is the use of an auxiliary time series model. In estimation the parameters of the structural model are chosen such that when this model is simulated it generates estimates of the auxiliary model similar to those obtained from the actual data. The optimal choices of parameters for the structural model are those that minimise the distance between a given function of the two sets of estimated coefficients of the auxiliary model. Common choices of this function are the actual coefficients, the scores or the impulse response functions. In model evaluation the parameters of the structural model are taken as given. The aim is to compare the performance of the auxiliary model estimated on simulated data derived from the given estimates of a structural model - which is taken as a 'true' model of the economy, the null hypothesis - with the performance of the auxiliary model when estimated from the actual data. If the structural model is correct then its predictions about the impulse responses, moments and time series properties of the data should statistically match those based on the actual data. The comparison is based on the distributions of the two sets of parameter estimates of the auxiliary model, or of functions of these estimates.

The testing procedure thus involves first constructing the errors implied by the previously estimated/calibrated structural model and the data. These are called the structural errors and are backed out directly from the model equations and the data. ${ }^{4}$ These errors are then bootstrapped and used to generate for each bootstrap new data based on the structural model. An auxiliary time series model is then fitted to each set of data and the sampling distribution of the coefficients of the auxiliary time series model is obtained from these estimates of the auxiliary model. A Wald statistic is computed to determine whether functions of the parameters of the time series model estimated on the actual data lie in some confidence interval implied by this sampling distribution.

The auxiliary model should be a process that would describe the evolution of the data under any relevant model. It is known that for non-stationary data the reduced form of a macro model is a VARMA where non-stationary forcing variables enter as conditioning variables to achieve cointegration (i.e. ensuring that the stochastic trends in the endogenous vector are picked up so that the errors in the VAR are

\footnotetext{
${ }^{4}$ Some equations may involve calculation of expectations. The method we use here to initiate the tests is the robust instrumental variables estimation suggested by McCallum (1976) and Wickens (1982): we set the lagged endogenous data as instruments and calculate the fitted values from the VAR we use as the auxiliary model in what follows'Once the search procedure (effectively indirect estimation) has converged on the best model parameters, we then move to generating the expectations exactly implied by the parameters and the data, and use these to calculate the errors, which are then the exact errors implied by the model and data. The reason we do not use this 'exact' method at the start is that initially when the model is far from the data, the expectations generated are also far from the true ones, so that the errors are exaggerated and the procedure may not converge.
} 
(IS curve)

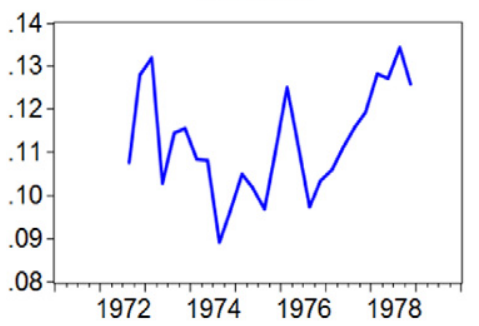

(Phillips curve)

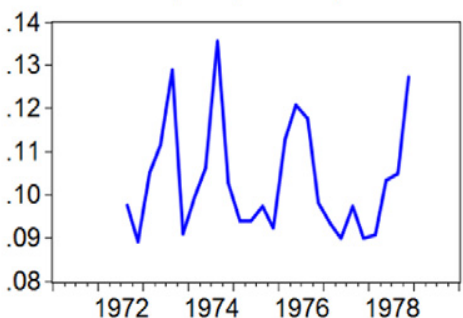

(Weighted inflation equation)

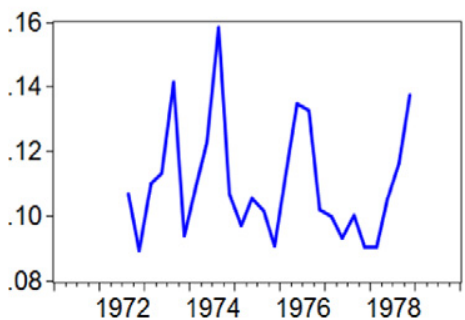

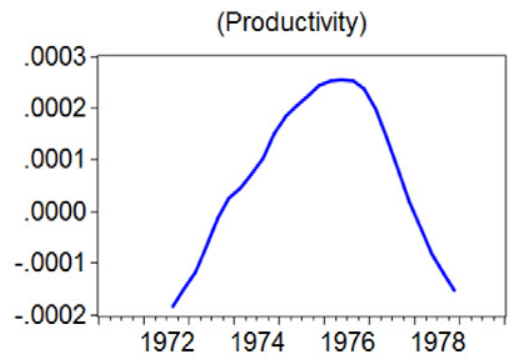

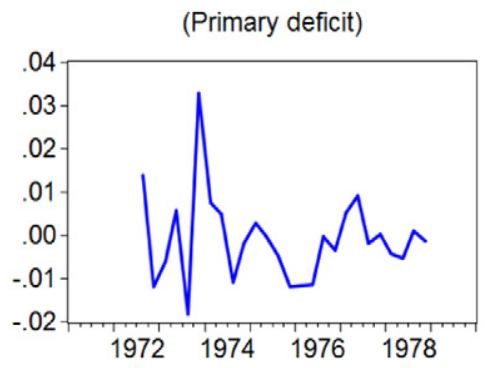

Fig. 14. Structural errors in 1970s (Weighted model).

stationary). This in turn can be approximated as a VECM - see Appendix A for details. So following Meenagh et al. (2012) we use as the auxiliary model a VECM which we reexpress as a VARX(1) for the four macro variables (interest rate, output, inflation and the primary budget deficit), with a time trend and with $y_{t}^{*}$ entered as the exogenous nonstationary 'productivity trend' (these two elements having the effect of achieving cointegration). Thus our auxiliary model in practice is given by: $y_{t}=[I-K] y_{t-1}+\gamma \bar{x}_{t-1}+g t+v_{t}$ where $\bar{x}_{t-1}$ is the stochastic trend in productivity, $g t$ are the deterministic trends, and $v_{t}$ are the VECM innovations. We treat as the descriptors of the data all the VARX coefficients and the VARX error variances; we exclude the time

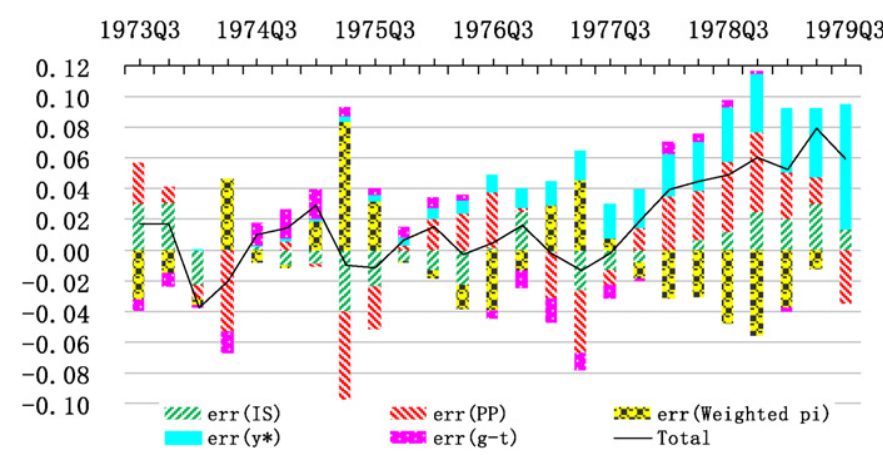

Fig. 15. Timeline for output (Weighted model).

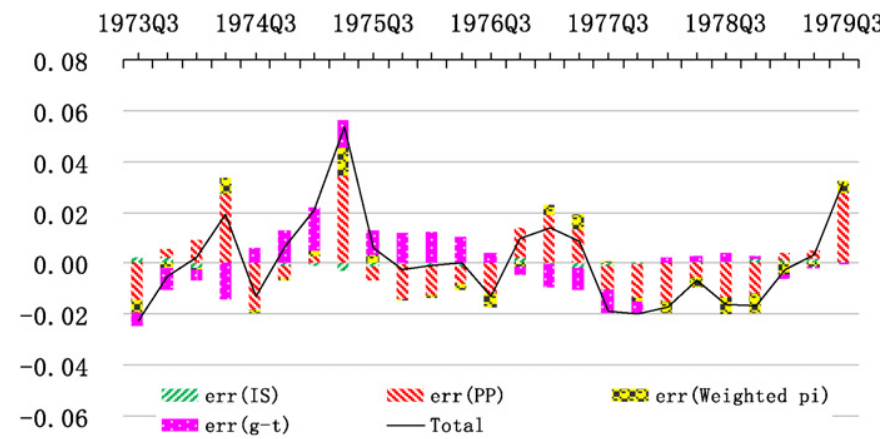

Fig. 16. Timeline for inflation (Weighted model). trends since we are not concerned with the growth paths. From these descriptors a Wald statistic may be computed that acts as a test at a given confidence level of whether the observed dynamics, volatility and cointegrating relations of the chosen variables are explained by the DSGE-model-simulated joint distribution of these. This Wald statistic is given by:

$(\Phi-\bar{\Phi})^{\prime} \sum_{(\Phi \Phi)}^{-1}(\Phi-\bar{\Phi})$

where $\Phi$ is the vector of VARX estimates of the chosen descriptors

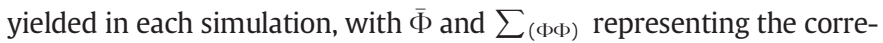
sponding sample means and variance-covariance matrix of these calculated across simulations, respectively.

The joint distribution of the $\Phi$ is obtained by bootstrapping the innovations implied by the data and the theoretical model; it is therefore an estimate of the small sample distribution. ${ }^{5}$ Such a distribution is generally more accurate for small samples than the asymptotic distribution; it is also shown to be consistent by Le et al. (2011) given that the Wald statistic is 'asymptotically pivotal'; they also showed it had quite good accuracy in small sample Monte Carlo experiments. ${ }^{6}$

This testing procedure is applied to a set of (structural) parameters put forward as the true ones $\left(H_{0}\right.$, the null hypothesis); they can be derived from calibration, estimation, or both. However derived, the test then asks: could these coefficients within this model structure be the true (numerical) model generating the data? Of course only one true model with one set of coefficients is possible. Nevertheless we may have chosen coefficients that are not exactly right numerically, so that the same model with other coefficient values could be correct. Only when we have examined the model with all coefficient values that are feasible within the model theory will we have properly tested it. For this reason we extend our procedure by a further search algorithm, in which we seek other coefficient sets that minimise the Wald test statistic - in doing this we are carrying out indirect estimation. The indirect estimates of the model are consistent and asymptotically normal, in common with full information maximum likelihood (FIML) estimates

\footnotetext{
5 The bootstraps in our tests are all drawn as time vectors so contemporaneous correlations between the innovations are preserved.

${ }^{6}$ Specifically, they found on stationary data that the bias due to bootstrapping was just over $2 \%$ at the $95 \%$ confidence level and $0.6 \%$ at the $99 \%$ level. Meenagh et al. (2012) found even greater accuracy in Monte Carlo experiments on nonstationary data.
} 


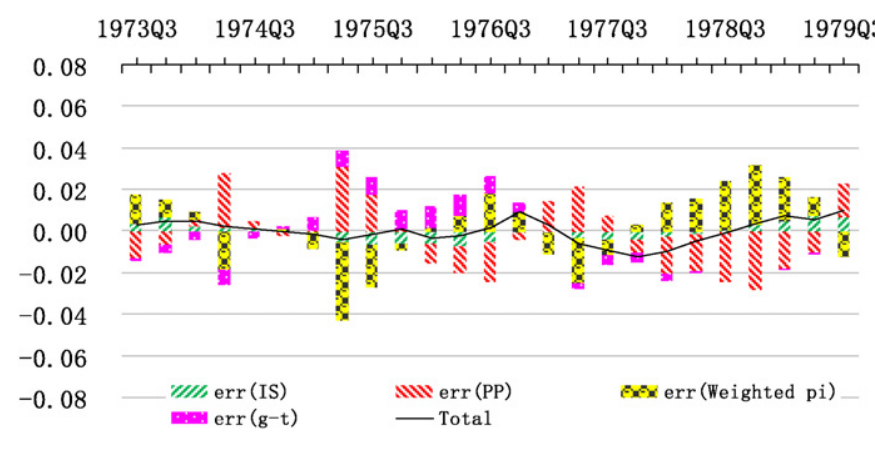

Fig. 17. Timeline for nom. Int. rates (Weighted model).

- see Smith (1993); Gregory and Smith (1991, 1993); Gourieroux et al. (1993); Gourieroux and Monfort (1995) and Canova (2005).

Thus we calculate the minimum-value full Wald statistic for each model using a powerful algorithm based on Simulated Annealing (SA) due to Ingber (1996) in which search takes place over a wide range around the initial values, with optimising search accompanied by random jumps around the space. We find this algorithm, designed to avoid local minima in a procedure similar to processes used to cool steel, improves substantially here on a standard optimisation algorithm. Our estimation method involves taking an initial calibrated set of model parameters (excluding error processes), extract the resulting residuals from the data by the method desribed above, find their implied autoregressive coefficients ( $A R(1)$ here) and then bootstrap the implied innovations with this full set of parameters to find the implied Wald value. This is then minimised by the SA algorithm. The merit of this extended procedure is that we are comparing the estimated versions of each model type when finally doing our comparison of model compatibility with the data. It should be emphasised that these numerical methods are a convenient way to compute the Indirect Inference estimates of the model parameters which are presented in the results which follow.

\subsection{Model identification}

It would be reasonable to ask whether a macroeconomic model of a few equations like the ones here can be considered to be identified. Le et al. (2013) examined this issue for a three-equation New Keynesian model of the sort being considered here. They found that it was likely to be heavily over-identified. Thus there were many more coefficients

Table 13

Indirect estimates of the models: Weighted vs FTPL and Orthodox (1979-1990).

\begin{tabular}{|c|c|c|c|}
\hline Model parameter & FTPL & Orthodox Taylor & Weighted model \\
\hline$\theta$ & 4.29 & 2.13 & 4.13 \\
\hline$\beta$ & \multicolumn{3}{|c|}{----fixed at 0.99--_- } \\
\hline$\sigma$ & 1.79 & 0.27 & 0.76 \\
\hline к & 0.1 & - & 0.31 \\
\hline$\rho$ & - & 0.81 & 0.92 \\
\hline$\phi_{\pi}$ & - & 3.67 & 3.63 \\
\hline$\phi_{\text {xgap }}$ & - & 0.18 & 0.09 \\
\hline$\delta$ & - & 0.66 & 0.96 \\
\hline$c^{y^{*}}$ & \multirow{2}{*}{\multicolumn{3}{|c|}{$\begin{array}{l}---- \text { fixed at } 0.0005---- \\
---- \text { fixed at } 0.97----\end{array}$}} \\
\hline$\gamma$ & & & \\
\hline Weight & - & - & 0.44 \\
\hline \multicolumn{4}{|c|}{ Shock persistence (rho's) } \\
\hline$e r r^{p p}$ & 0.53 & 0.39 & 0.5 \\
\hline$e r r^{I S}$ & 0.64 & 0.86 & 0.83 \\
\hline$e r r^{y^{*}}$ & 0.94 & 0.94 & 0.94 \\
\hline$e r r^{g-t}$ & -0.22 & 0.15 & 0.44 \\
\hline$e r r^{\pi}$ & 0.19 & - & - \\
\hline$e r r^{R^{S}}$ & - & -0.09 & - \\
\hline err Weighted $\pi$ & - & - & -0.13 \\
\hline
\end{tabular}

Table 14

$P$-values of the models: weighted vs FTPL and Orthodox (1979-1990).

\begin{tabular}{llll}
\hline Elements tested & FTPL & Orthodox & Weighted model \\
\hline Dynamics (VARX coeff. only) & 0.083 & 0.16 & 0.272 \\
Volatility (VARX resid. only) & 0.493 & 0.886 & 0.669 \\
All elements (VARX coeff. + resid.) & 0.115 & 0.227 & 0.365 \\
\hline
\end{tabular}

Note: $p$-value $=(100-$ Wald percentile $) / 100$.

in the reduced form than in the structural model; under normal assumptions this should give several sets of estimates of the structural coefficients from the reduced form. With enough data these sets would coincide and so even a partial reduced form should be sufficient to yield a set of structural parameter estimates. In that paper they went further and sought to find alternative structural parameter sets that could generate the same reduced form; using indirect inference they were able to establish that no other sets could exist. These results suggest that we can regard each of the two models here as overidentified, implying that there is no chance of confusing the reduced form of the one with the reduced form of the other.

We can check the identification of our two models using exactly the same method. We carry out a Monte Carlo experiment in which we assume that the FTPL model is true (we give it the same parameters as those we later estimate for it) and using the FTPL error properties we generate 1000 samples of data from it (of the same length as in our 1970s sample here - 28 quarters) and calculate the VARX approximate reduced form from it. We now ask whether any Orthodox model could generate the same data and hence the same VARX reduced form, using the indirect inference test at 95\% confidence; if indeed it could do so, thus effectively being the same model, then we would reject exactly the same percent of the time as we reject the true FTPL model - namely $5 \%$. In fact we reject it for about $25 \%$ of the samples; thus it cannot be the same model (Table 2). We also did the reverse, and found the same (rejecting it at about the same rate). In doing this check we have searched over a wide range of parameter values using the Simulated Annealing algorithm, starting from the estimated parameters.

This test shows clearly that these two models cannot be confused with each other under conditions where data availability is not a problem - i.e., under the asymptotic conditions we assume for identification. Thus they are not 'observationally equivalent', even though, as we show below, their data representations in VARX form are similar. To distinguish them one needs to estimate and test them in full, which we now go on to do.

\section{Data and Test Results for the 1970s}

We limit our focus for the 1970s to the period between 1972-1979 during which the FTPL could be a potential candidate given the economic background. We use unfiltered (but seasonally adjusted) data from official sources. We define as $R_{t}^{s}$ the Bank of England Minimum Lending Rates, and as $\pi_{t}$ the percentage change in CPI as per the OECD data, both in quarterly term. We use for $y_{t}$ the real GDP level in natural logorithm from the Office for National Statistics (ONS), and for $y_{t}^{*}$ its trend values as suggested by the $\mathrm{H}-\mathrm{P}$ filter. The primary deficit ratio $g-t$ is simply the difference between $G / G D P$ and $T / G D P$, where $G$ and $T$ are respectively

Table 15

Variance decomposition (weighted model; 1979-1990).

\begin{tabular}{|c|c|c|c|c|}
\hline Unit: \% & $\mathrm{y}$ & $\pi$ & $R^{s}$ & $r$ \\
\hline$e r r^{I S}:$ & 0.5 & 24.2 & 82 & 68.4 \\
\hline$e r r^{P P}:$ & 37.5 & 13.4 & 15.1 & 27.5 \\
\hline errWeighted $\pi$ : & 1.2 & 60.1 & 2.7 & 4.1 \\
\hline$e r r^{y^{*}}:$ & 60.8 & 0 & 0 & 0 \\
\hline$e r r^{g-t}$ : & 0 & 2.3 & 0.2 & 0 \\
\hline Total: & 100 & 100 & 100 & 100 \\
\hline
\end{tabular}




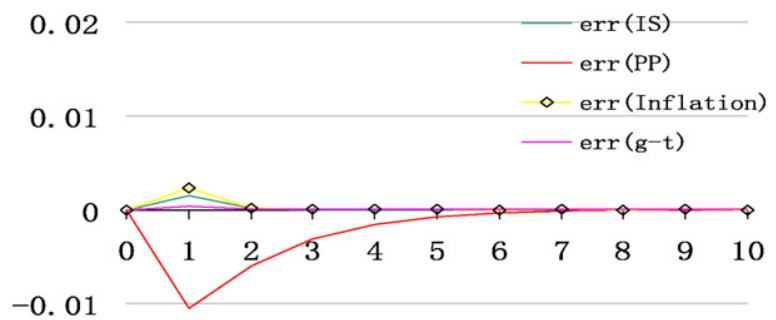

$-0.02$

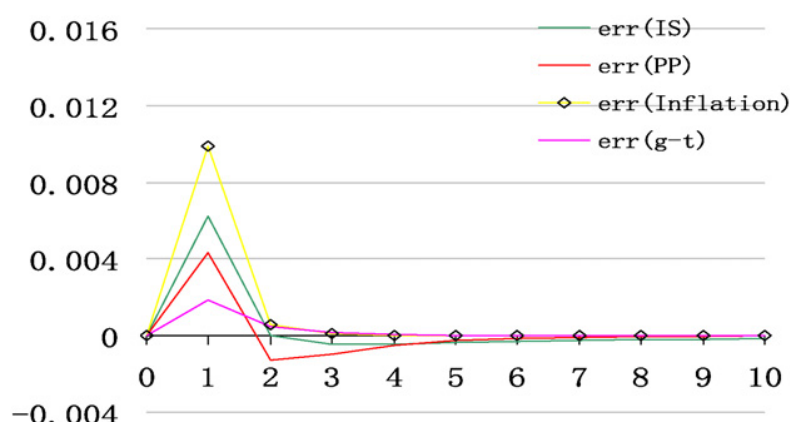

Fig. 19. IRFs - Inflation (Weighted model).

economy is orthogonal to the fiscal deficit but there is considerable simultaneity otherwise. Shocks to demand (IS), supply (PP) and monetary policy $\left(R^{S}\right)$ each move all four macro variables in a relatively normal way, as can be seen from the impulse responses ${ }^{8}$ (Figs. 6-9) and also the variance decomposition (carried out just as for the FTPL) in Table 5. To replicate the data behaviour in this episode, with its large swings in inflation, the model finds large monetary policy $\left(e r r^{R^{s}}\right)$ shocks which need to be moderated by Taylor Rule interest rate responses to limit inflation variation; these shocks dominate inflation variance which triggers the Taylor Rule response limiting the effects on real interest rates and output. Demand (err ${ }^{I S}$ ) shocks trigger inflation and Taylor Rule responses, so largely affecting interest rate variance. Supply $\left(e r r^{P P}\right)$ shocks trigger sharp inflation responses which are largely neutralised by real interest rate responses; these in turn destabilise output, given the flat IS curve.

\subsubsection{What do the tests show about the two models?}

We may now consider the way in which each model replicates the VARX estimates on the data, as shown in Table 6.

We can see from this Table that each model implies ranges for many of the VARX coefficients that are fairly similar. However, we must stress that that it is their joint distribution that is used in the Wald statistic: we ask via the Wald test whether the joint distribution of each model could contain the joint values found on the data. These tests are shown in Table 7. They show the percentile of the Wald distribution where the data-based VARX lies (the 'Wald percentile') and also the $p$-value (= [100 minus this percentile]/100). Plainly the two models differ substantially in their ability to match the coefficients jointly, with FTPL's p-value around twice that of the Orthodox.

The table suggests that when the models are asked to fit all elements of the VARX, both models pass the Wald test at a $95 \%$ confidence level, though the FTPL has a $p$-value about double that of the Orthodox model. Hence if we limit ourselves to these two models the FTPL is ranked well above the Orthodox for this period. Before we consider further how we should react to this result, we consider whether other estimation and testing methods can shed more light on the model rankings.

\subsection{Bayesian analysis of the two models}

Bayesian estimation methods have become widespread in macromodelling and so it is appropriate that we ask what contribution they can make to our investigation here. There are two main approaches we can take: with strong priors and with flat or uninformative priors. In the latter case the Bayesian method becomes FIML and we can use the Likelihood Ratio in the usual classical manner. In the former the model posterior likelihood and hence ranking involves both the priors and the data likelihood. We report the two approaches in turn.

\footnotetext{
${ }^{8}$ In this model the effect of deficit errors are nil on output, inflation, and both nominal and real interest rates.
}

\footnotetext{
${ }^{7}$ In this model the effect of IS curve shock on output and inflation is nil.
} 


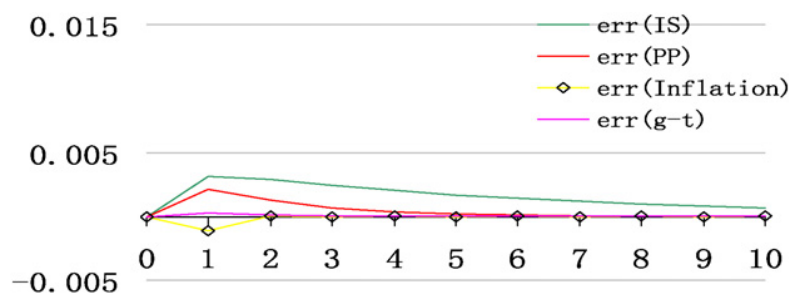

$-0.015$

Fig. 20. IRFs - Nom. int. rates (Weighted model).

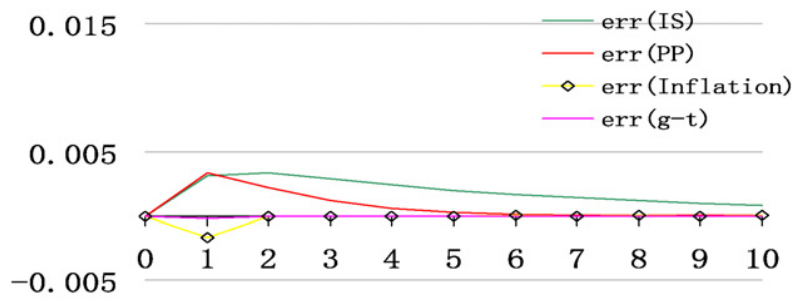

$-0.015$

Fig. 21. IRFs - Real int. rates (Weighted model).

As is plain from the listing in Table 8, for strong priors (that are chosen to be in favour of either the FTPL model or the Orthodox model) the marginal data likelihoods are extremely different from the viewpoint of ranking the two models based on the Bayes factor. In this case we are able to obtain a strong ranking of the models on each set of priors; but the rankings contradict each other, with the priors effectively setting the rank order. Plainly we cannot use these estimates to rank the models without begging the question of which model and associated priors is correct.

If we turn to the FIML estimates where the priors are flat and so irrelevant, we encounter the besetting problem of flat likelihood in small samples. We obtain model estimates that are quite different from the
II estimates as we show in (Table 9). Yet when we compute the Likelihood Ratio, LR, of these estimates (against the VARX on the data) we find that both models fail to be rejected by the data on their ML estimates and furthermore on their II estimates the LR $p$-values of the Orthodox model are somewhat higher, suggesting that the ML estimator has great difficulty in locating its optimal parameter values. The II estimator has much lower small sample bias (Le et al., 2012) and here is generally better determined than the ML estimator; we use it in what follows. But the general conclusion from the ML estimates is consistent with those from the II estimates: that neither model is rejected and that the FTPL model is ranked above the Orthodox on ML estimates by the LR $p$-values, just as it is on II $p$-values on II estimates.

Our conclusion from these various methods of evaluation is that we cannot rank the models using strong priors because we obtain contradictory results depending on which priors we use. We may use ML estimation (flat priors) and the LR test but this like the II test fails to reject either model. However, the fact that we cannot reject either model with any confidence suggest we should look for some model, closer to the truth, that somehow combines the two models, so accounting for the fact that both have some truth in them. We now go on to argue that there is a case for such a model.

\section{A combined model?}

This was, as should have been clear from our earlier discussion of the context, a period of great uncertainty in UK economics and politics; in 1975 there was even a proposal by certain Labour politicians led by Tony Benn, a leading minister in the government, to install a siege economy (effectively to insulate an FTPL strategy from external pressures), and this was only narrowly defeated within the Labour government. It may therefore well be that people gave some probability to an FTPL regime continuing and some to an orthodox regime reasserting itself - in the manner described by Leeper (1991).

Our II results for the two models above suggest that inflation behaviour was being influenced by expectations of two potential regimes each with a certain probability. Inflation in this model equals (today's) expected inflation because no information lag is assumed. Hence we can think of the FTPL inflation equation as showing the inflation that would be expected (and would also occur) at time $t$ if the FTPL regime was in operation. Similarly for the Orthodox model we can think of the Taylor Rule equation as defining the inflation that would be permitted by the rule (and so would also occur) at prevailing interest rates;
(IS curve)

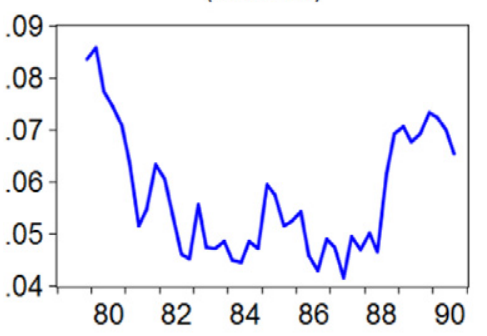

(Phillips curve)

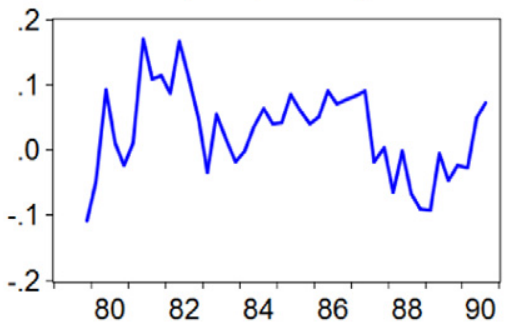

(Weighted inflation equation)

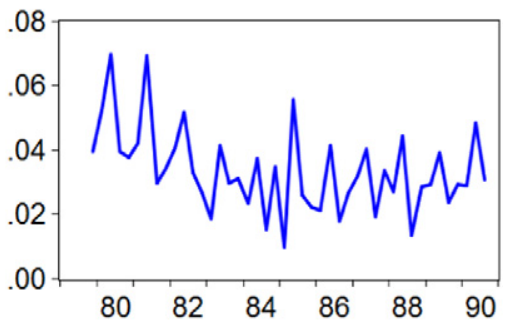

(Productivity)

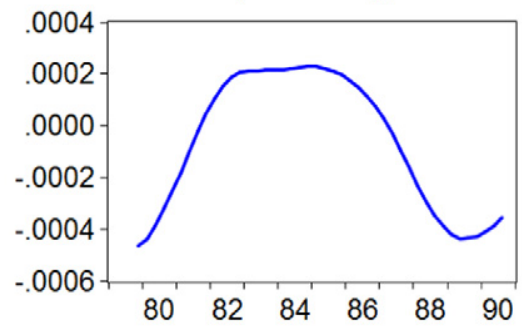

(Primary deficit)

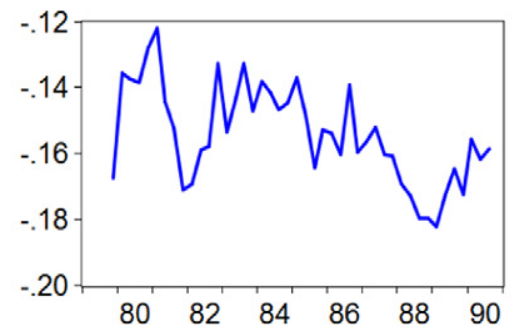

Fig. 22. Structural errors in 1980s (Weighted model). 


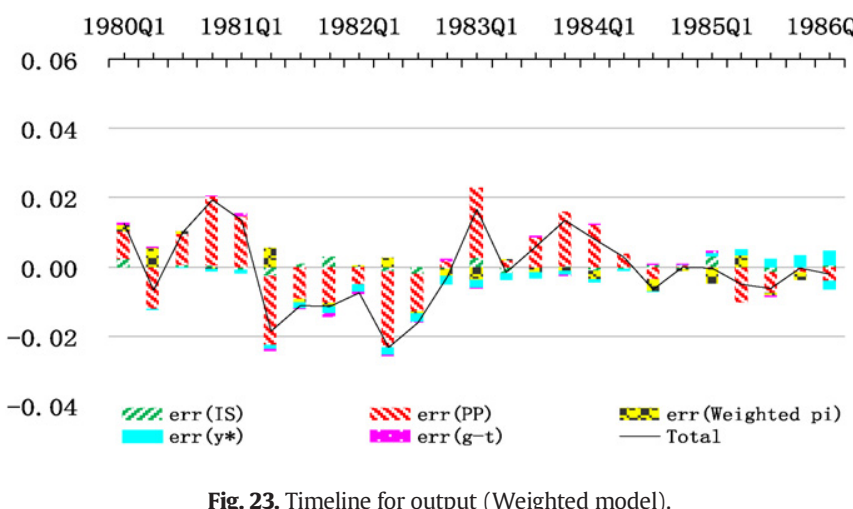

Fig. 23. Timeline for output (Weighted model).

thus this would be the inflation expected if the Orthodox regime was prevailing. We can therefore create a model in which inflation expectations are governed by the probability-weighted inflation rate under the two regimes; this will be also the actual inflation, since actual=expected. In this model inflation will thus be a weighted combination of the two models' inflation equations - the FTPL and the Taylor Rule equations - these are Eqs (12) and (12b) respectively and we now replace them both with:

$$
\begin{aligned}
\pi_{t} & =W^{\mathrm{FTPL}} \kappa\left(g_{t}-t_{t}\right) \\
& +\left[1-W^{\mathrm{FTPL}} \frac{1}{\phi_{\pi}} \frac{1}{(1-\rho)}\left(R_{t}-\rho R_{t-1}\right)-\phi_{\text {xgap }}\left(y_{t}-y_{t}^{*}\right)-\alpha\right]+e r r_{t}^{\text {Weighted } \pi}
\end{aligned}
$$

Given that inflation is determined by the probability-weighted average of each regime's own inflation outcome, we now have a composite inflation error - which in principle consists of the weighted combination of the two regime error processes plus any temporary deviations of inflation from this weighted combination (e.g. due to variation in the weight). Since we cannot observe what the inflation rate actually was in each regime, only the average outcome, we can only observe a composite error.

All the other equations are the same, with the exception of the fiscal deficit equation which has an $A R$ coefficient $(\delta=0.007$, as reported in Table 3 ) that is so close to zero that it cannot resolve the uncertainty about which regime is operating; we allow it to be determined by the model estimation.

When we examine the results of this weighted model (as we report in Tables 10 and 11 in comparison to the earlier results), we see that it improves substantially on both models alone, with a $p$-value almost double that of the FTPL and almost four times that of the Orthodox. The model now adopts a very flat Phillips Curve, a steep IS Curve, and a tough Taylor Rule (with a high response to inflation and a moderate response to the output gap). Given the 0.58 weight on FTPL, the effect of the FTPL deficit mechanism on inflation (now $\kappa \times$ Weight) is a bit

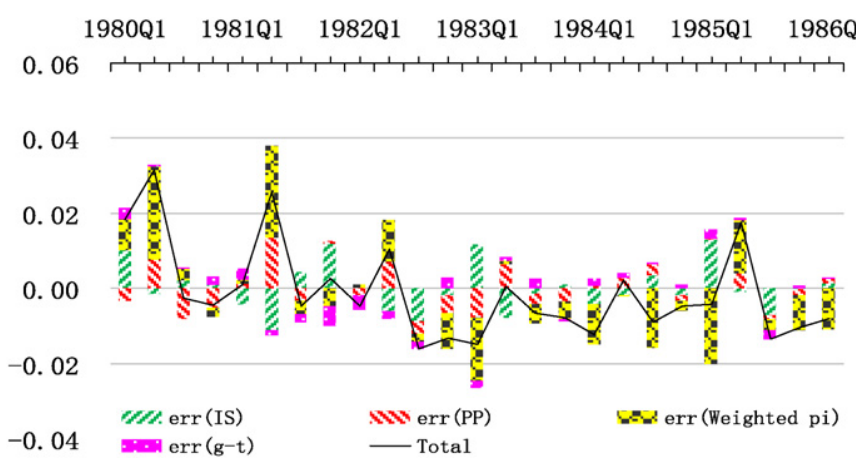

Fig. 24. Timeline for ination (Weighted model).

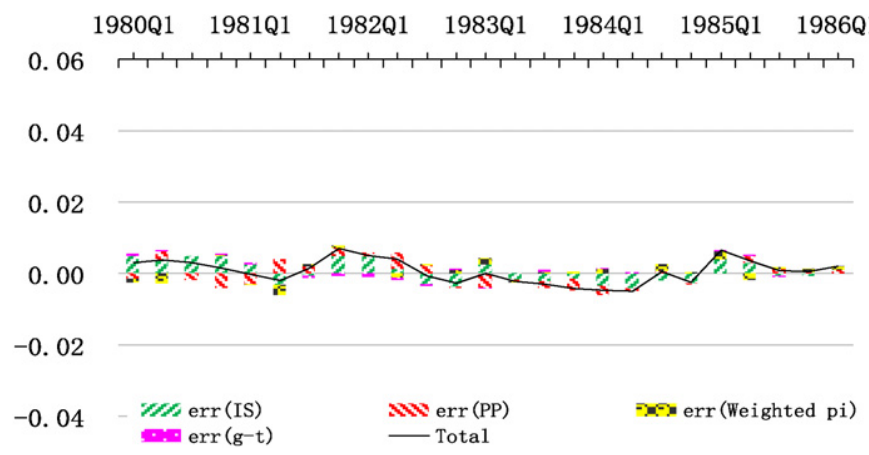

Fig. 25. Timeline for nom. Int. rates.

higher than that in the FTPL model, implying that fiscal policy has a strong influence still on inflation.

The blend of Orthodox with FTPL is revealed in the IRFs (Figs. 10-13). The IS and PP shocks affect the economy much as in the Orthodox case. A positive weighted inflation error is a combination of 1) a direct temporary shock to inflation as in the FTPL model and 2) an easing of monetary policy in the Taylor Rule error. The fiscal shock behaves as in the FTPL model, strongly affecting inflation and nominal interest rates.

The resulting variance decomposition (Table 12) gives the supply shock and the weighted inflation shocks about an equal role in output variability - the latter including as we have seen both the monetary policy and any exogenous inflation shock. These two shocks also share the main role in real interest rate variability. For inflation variability the fiscal shock becomes dominant, with the supply shock providing the rest. Nominal interest rate variability thus reflects a roughly similar role for supply, inflation and fiscal shocks. What we see here in the weighted model is that the FTPL influences remain important.

In the next section we review the implications of this successful weighted model for the causes of what happened quarter by quarter. Clearly, huge errors in policy were made, to permit the large rise in inflation and the prolonged recession both to occur during the mid1970s. In our final concluding section, we reflect on the policy lessons and how they were absorbed subsequently in UK political choices.

\section{A time-line of the UK 1970s episode according to the weighted model}

We see first the errors backed out period by period in Fig. 14. Begin with the inflation error in the weighted FTPL/Taylor Rule equation. This is some combination of monetary policy and exogenous inflation (notably commodity price) shocks; the 1973 and 1974 peaks were both periods of expansionary money and surging commodity prices. 1977's low point corresponds to the IMF visit, which tightened money sharply. Next, we note that the PP shock mirrors this weighted inflation error closely; this is because with a very flat Phillips Curve movements in inflation are governed almost solely by expected inflation for next quarter; but since the fiscal deficit is close to a random walk this turns out to be very close to current expected inflation which too is dominated by the current fiscal deficit. The IS shock turns negative in the mid-1970s before recovering in the late 1970s. The fiscal deficit shock is large and positive early on before being restrained later in the period.

In the timeline for output (Fig. 15) we see that all these shocks play a part; the dominant role, as foreshadowed by our variance decomposition, is taken by the supply and inflation shocks but these essentially cancel each other out, leaving the IS shock as the factor creating recession and the productivity shock assisting it in generating later recovery. For inflation (Fig. 16) the fiscal shock is the key factor generating the sharp inflation explosion from 1973-5, aided by the supply shock. For interest rates (Fig. 17), fiscal, supply and inflation shocks all three are 
major factors, but tend to cancel each other out, so that interest rates move less than one might expect given the sharp rise in inflation in mid-1975; this is consistent with the model's finding that monetary policy itself has an inadequate response to inflation during the period (the weight on the Taylor Rule of 0.42 times the inflation response of 1.84 is only 0.77 ).

Thus the overall picture of the period from our weighted model is that the fiscal deficit was a key factor in driving inflation expectations and that monetary policy in practice did little to moderate these; interest rates varied inadequately. Output was the victim of poor productivity growth and the demand shocks of the mid-1970s, with these both improving somewhat later in the period.

From these timelines it is clear that poor expected macro policy choices, both fiscal and monetary, reinforced the bad results already created by the poor growth of productivity. The two factors together produced economic results so bad that the British voters backed Margaret Thatcher's radical policy changes over a whole decade, embracing not merely macro-policy but also supply-side policy reforms. Whether the voters would have backed her had the economy not been in such a parlous condition in 1979 is a matter of intense interest for political economy but clearly lies well outside the scope of this paper.

\section{Analysis of the 1980s}

We now turn to a comparative analysis of the 1980s episode (19791990) in which the Thatcher government changed the macro-economic policy regime. According to most accounts this sets up an 'active' monetary policy designed to bear down on inflation and a 'passive' or Ricardian fiscal policy designed to ensure solvency; another way of expressing this used in commentary at the time (e.g. Minford, 1980; Sargent and Wallace, 1981) was that fiscal policy should not threaten monetary policy by undermining confidence in solvency. If these widely-accepted accounts are correct, we should find according to our empirical II method that the 1980s data give opposite results to the1970s. We should find that the FTPL model performs less well and that its weight in any weighted model is much smaller while the effect of fiscal behaviour on inflation should also be small.

In this section we do not repeat our analysis of Bayesian and ML estimates, because for the same reasons as in the 1970s these give unhelpful results. We focus solely on the Indirect Inference estimates in what follows.

As expected, we find from our 1980s estimates that indeed the FTPL theory while not rejected does less well than the Orthodox in explaining the data behaviour; and that the weighted model implies much less of an effect of fiscal policy.

Our results (for data from 1979 to 1990) are shown in Tables 13 to 15. Once again both models fail to be rejected. But now the Orthodox model is ranked higher than the FTPL model by $p$-value. Also the weighted model again has a $p$-value substantially greater than either single model, this time nearly double that of the Orthodox and nearly four times that of the FTPL. We can conclude from this that in spite of the new government's announced intentions uncertainty remained about the two regimes and whether specifically fiscal policy would remain under control. The weight on the FTPL regime remained as high as 0.44 .

Thus it might appear that the 1980s were not so different as widely thought from the 1970s. Nevertheless, the effect of the fiscal deficit on the economy fades from the picture in the weighted model. Its direct effect on inflation $(\kappa \times$ Weight $)$ falls from 0.47 in the 1970 s to 0.14 in the 1980s. In the variance decomposition its role in influencing the economy's behaviour virtually disappears, its share of inflation variance falling to $2.3 \%$ and of nominal interest rate variance to $0.2 \%$ (See also the impulse responses as we summarise in Figs. 18 to 21). We can interpret this as implying that although people were worried that fiscal policy might matter for inflation resurgence and hence assigned it a role, in practice its behaviour was tightly controlled so that these fears were not realised. At the same time the 'monetarist' tag attached to the new government is borne out by the high monetary response to inflation (this being $[1-$ Weight $] \times \phi_{\pi}=$ 2.03).

Interestingly, this interpretation is reinforced by the well-known nervousness about fiscal deficits of the Thatcher government, famously exhibited in the controversially tight 1981 budget. In effect the Thatcher ministers were deeply concerned to lay to rest doubts about their fiscal policy intentions so that their perceived monetary toughness towards inflation would not be undermined.

What we see in the model behaviour (via decomposing the effect of historical shocks, as in Figs. 22 to 25) on the 1980s is a much diminished role of fiscal shocks on the economy, brought about by the change in regime towards the greater dominance of orthodox monetary policy which keeps inflation under tighter control. As a result the inflationary shock no longer affects output or interest rates much, by contrast with the 1980s when it was the dominant factor disturbing them.

\section{Conclusions}

In this paper we have examined an episode of UK history, the 1970s, when fiscal policy may have been set without thought for future solvency implications and monetary policy may have been entirely accommodative - a case of the Fiscal Theory of the Price Level (FTPL). Because the data implications of this theory are qualitatively similar to those of the Orthodox theory in which monetary policy is set by a Taylor Rule to hit an inflation target and fiscal policy is set to achieve solvency at that inflation rate, we have set up the two theories as rival structural models and tested each against the behaviour found in the data, by the method of Indirect Inference (our efforts to use Bayesian or Maximum Likelihood estimation could not distinguish so convincingly between the two models). Our finding is that neither model is rejected by the data but that the FTPL model can account much better for the data behaviour than the Orthodox; nevertheless by far the best account of the period assumes that expectations were a probability-weighted combination of the two regimes. The policies pursued in this episode generated generally high as well as volatile inflation, together with weak productivity growth and a long-lived recession. They paved the way for a decisive change of approach to both fiscal and monetary policy after the election of 1979. However we also found when examining the 1980s that there remained a considerable degree of policy uncertainty so that expectations about fiscal policy continued to play a key role; nervousness about this influenced the Thatcher government's policies to bring fiscal deficits down steadily so that in practice the role of fiscal policy in the economy's behaviour was minimised. In sum the evidence of these two decades of UK history suggest that fiscal deficits were key to the macro-economic crises of the 1970s and bringing them under control was important, alongside tighter monetary policy, in restoring stability in the 1980 s.

\section{Appendix A. VECM/VARX representation of a DSGE model}

Following Meenagh et al. (2012), we can say that after loglinearisation a DSGE model can usually be written in the form

$A(L) y_{t}=B E_{t} y_{t+1}+C(L) x_{t}+D(L) e_{t}$

where $y_{t}$ are $p$ endogenous variables and $x_{t}$ are $q$ exogenous variables which we assume are driven by

$\Delta x_{t}=a(L) \Delta x_{t-1}+d+c(L) \varepsilon_{t}$.

The exogenous variables may contain both observable and unobservable variables such as a technology shock. The disturbances 
$e_{t}$ and $\varepsilon_{t}$ are both i.i.d. variables with zero means. It follows that both $y_{t}$ and $x_{t}$ are non-stationary. $L$ denotes the lag operator, thus, $z_{t-s}=$ $L^{s} z_{t}$, and $A(L), B(L)$ etc. are polynomial functions with roots outside the unit circle.

The general solution of $y_{t}$ is

$y_{t}=G(L) y_{t-1}+H(L) x_{t}+f+M(L) e_{t}+N(L) \varepsilon_{t}$.

where the polynomial functions have roots outside the unit circle. As $y_{t}$ and $x_{t}$ are non-stationary, the solution has the $p$ cointegration relations:

$\begin{aligned} y_{t} & =[I-G(1)]^{-1}\left[H(1) x_{t}+f\right] \\ & =\prod x_{t}+g \cdot A 4\end{aligned}$

The long-run solution to the model is

$\bar{y}_{t}=\Pi \bar{x}_{t}+g$

$\bar{x}_{t}=[1-a(1)]^{-1}\left[d t+c(1) \xi_{t}\right]$

$\xi_{t}=\Sigma_{i=0}^{t-1} \varepsilon_{t-s}$

Hence the long-run solution to $x_{t}$, namely, $\bar{x}_{t}=\bar{x}_{t}^{D}+\bar{x}_{t}^{S}$ has a deterministic trend $\bar{x}_{t}^{D}=[1-a(1)]^{-1} d t$ and a stochastic trend $\bar{x}_{t}^{S}=$ $[1-a(1)]^{-1} c(1) \xi_{t}$.

The solution for $y_{t}$ can therefore be re-written as the VECM:

$$
\begin{aligned}
\Delta y_{t}= & -[I-G(1)]\left(y_{t-1}-\Pi x_{t-1}\right)+P(L) \Delta y_{t-1}+Q(L) \Delta x_{t}+f+M(L) e_{t} \\
& +N(L) \varepsilon_{t}=-[I-G(1)]\left(y_{t-1}-\Pi x_{t-1}\right)+P(L) \Delta y_{t-1}+Q(L) \Delta x_{t} \\
& +f+\omega_{t} A 5 \omega_{t}=M(L) e_{t}+N(L) \varepsilon_{t}
\end{aligned}
$$

Hence, in general, the disturbance $\omega_{t}$ is a mixed moving average process. This suggests that the VECM can be approximated by the VARX:

$\Delta y_{t}=K\left(y_{t-1}-\Pi x_{t-1}\right)+R(L) \Delta y_{t-1}+S(L) \Delta x_{t}+g+\zeta_{t}$

where $\zeta_{t}$ is an i.i.d. zero-mean process.

As

$\bar{x}_{t}=\bar{x}_{t-1}+[1-a(1)]^{-1}\left[d+\varepsilon_{t}\right]$

the VECM can also be written as:

$\Delta y_{t}=K\left[\left(y_{t-1}-\bar{y}_{t-1}\right)-\Pi\left(x_{t-1}-\bar{x}_{t-1}\right)\right]+R(L) \Delta y_{t-1}+S(L) \Delta x_{t}+h+\zeta_{t}$.

Either Eqs. (A6) or (A7) can act as the auxiliary model. Here we focus on (A7); this distinguishes between the effect of the trend element in $x$ and the temporary deviation from its trend. In our models these two elements have different effects and so should be distinguished in the data to allow the greatest test discrimination.

It is possible to estimate (A7) in one stage by OLS. Meenagh et al. (2012) do Monte Carlo experiments to check this procedure and find it to be extremely accurate.

\section{References}

Afonso, A., 2000. Fiscal policy sustainability: some unpleasant European evidence. University of Lisbon Working Paper, 2000/12.

Bajo-Rubio, O., Daz-Roldán, C., Esteve, V., 2009. Deficit sustainability and inflation in EMU: an analysis from the Fiscal Theory of the Price Level. Eur. J. Polit. Econ. 25 (4), 525-539 (Elsevier). (December).

Bajo-Rubio, O., Daz-Roldán, C., Esteve, V., 2014. Deficit sustainability, and monetary versus fiscal dominance: the case of Spain, 1850-2000. J. Policy Model 36 (5), 924-937.

Ballabriga, F., Martinez-Mongay, C., 2003. Has EMU shifted monetary and fiscal policies? In: Buti, M. (Ed.), Monetary and Fiscal Policies in EMU. Cambridge University Press, Cambridge, pp. 246-272
Bergin, P., 2000. Fiscal solvency and price level determination in a monetary union. J. Monet. Econ. 45, 37-53.

Bianchi, F., 2012. Evolving monetary/fiscal policy mix in the United States. Am. Econ. Rev. 102 (3), 167-172.

Bianchi, F., Melosi, L., 2013. Dormant shocks and fiscal virtue. 2013 NBER Macroeconomics Annual.

Bohn, H., 1998. The behaviour of U.S. public debt and deficits. Q. J. Econ. 113 (3), 949-963. Buiter, W.H., 1999. The fallacy of the fiscal theory of the price level. CEPR Discussion Paper No. 2205. Centre for Economic Policy Research, London (August).

Buiter, W.H., 2002. The Fiscal Theory of the Price Level: a critique. Econ. J. 112, 459-480.

Canova, F., 2005. Methods for Applied Macroeconomic Research. Princeton University Press, Princeton.

Canzoneri, M.B., Cumby, R.E., Diba, B.T., 2001. Is the price level determined by the needs of fiscal solvency? Am. Econ. Rev. 91 (5), 1221-1238.

Carlstrom, C.T., Fuerst, T.S., 2000. The fiscal theory of the price level. Econ. Rev. (Q I), 22-32 (Federal Reserve Bank of Cleveland).

Christiano, L.J., Fitzgerald, T.J., 2000. Understanding the Fiscal Theory of the Price Level. Econ. Rev. 36 (2), 1-38 (Federal Reserve Bank of Cleveland).

Clarida, R., Gali, J., Gertler, M., 1999. The science of monetary policy: a New Keynesian perspective. J. Econ. Lit. 37 (4), 1661-1707.

Cochrane, J.H., 1999. A frictionless view of U.S. inflation', NBER chapters. NBER Macroeconomics Annual 1998 vol. 13. National Bureau of Economic Research, pp. 323-421.

Cochrane, J.H., 2001. Long term debt and optimal policy in the Fiscal Theory of the Price Level. Econometrica 69 (1), 69-116.

Cochrane, J.H., 2005. Money as stock. J. Monet. Econ. 52, 501-528.

Gourieroux, C., Monfort, A., 1995. Simulation Based Econometric Methods. CORE Lectures Series, Louvain-la-Neuve.

Gourieroux, C., Monfort, A., Renault, E., 1993. Indirect inference. J. Appl. Econ. 8, 85-118.

Gregory, A., Smith, G., 1991. Calibration as testing: Inference in simulated macro models. J. Bus. Econ. Stat. 9, 293-303.

Gregory, A., Smith, G., 1993. Calibration in macroeconomics. In: Maddala, G. (Ed.), Handbook of Statistics vol. 11. Elsevier, St. Louis, MO, pp. 703-719.

Hall, R.E., 1978. Stochastic implications of the life cycle-permanent income hypothesis: theory and evidence. J. Polit. Econ. 86, 971-988.

Ingber, L., 1996. Adaptive simulated annealing (ASA): lessons learned. Control. Cybern. $25,33$.

Kocherlakota, N and Phelan, C. (1999), 'Explaining the Fiscal Theory of the Price Level', (Federal Reserve Bank of Minneapolis) Q. Rev., Vol. 23, No. 4 pp. 14-23.

Le, V.P.M., Meenagh, D., Minford, P., Wickens, M.R., 2011. How much nominal rigidity is there in the US economy? Testing a new Keynesian DSGE model using indirect inference. J. Econ. Dyn. Control. (Elsevier, December).

Le, V.P.M., Meenagh, D., Minford, P., Wickens, M.R., 2012. Testing DSGE models by Indirect inference and other methods: some Monte Carlo experiments. Cardiff University Working Paper Series, E2012/15, June.

Le, V.P.M., Meenagh, D., Minford, P., Wickens, M.R., 2013. A Monte Carlo procedure for checking identification in DSGE models. Cardiff University Working Paper Series, E2013/4, March.

Leeper, E., 1991. Equilibria under active and passive monetary and fiscal policies. J. Monet. Econ. 27, 129-147.

Liu, C., Minford, P., 2014. Comparing behavioural and rational expectations for the US post-war economy. Econ. Model. 43 (C), 407-415.

Loyo, E., 2000. Tight money paradox on the loose: a fiscalist hyperinflation. Mimeo. J. F. Kennedy School of Government, Harvard University.

McCallum, B.T., 1976. Rational expectations and the natural rate hypothesis: some consistent estimates. Econometrica 44 (1), 43-52 (January).

McCallum, B.T., 2001. Indeterminacy, bubbles, and the Fiscal Theory of Price Level determination. J. Monet. Econ. 47 (1), 19-30.

McCallum, B.T., 2003. Is THE Fiscal Theory of the Price Level Learnable? Scott. J. Polit. Econ. 50, 634-649.

Meenagh, D., Minford, P., Theodoridis, K., 2009a. Testing a model of the UK by the method of indirect inference. Open Econ. Rev. 20 (2), 265-291 (Springer). (April).

Meenagh, D., Minford, P., Nowell, E., Sofat, P., Srinivasan, N.K., 2009b. Can the facts of UK inflation persistence be explained by nominal rigidity? Econ. Model. 26 (5), 978-992 (September).

Meenagh, D., Minford, P., Wickens, M.R., 2012. Testing macroeconomic models by indirect inference on unfiltered data. Cardiff University working paper, E2012/17.

Mèlitz, J., 2000. Some cross-country evidence about fiscal policy behavior and consequences for EMU. European Economic Reports and Studies, 2, pp. 3-21.

Minford, P., 1980. Evidence given to treasury and civil service committee, memorandum. Memoranda on Monetary Policy, HMSO 1980, Oral Evidence given in July 1980 in Committee's Third Report, Vol. II (Minutes of Evidence, HMSO, pp. 8-40).

Minford, P., 1993. Monetary policy in the other G7 countries: the United Kingdom. In: Fratianni, M., Salvatore, D. (Eds.), Monetary policy in Developed Economies (Handbook of comparative economic policies, Vol.). Greenwood Press, Westport, Conn. and London, pp. 405-431.

Nelson, E., 2003. UK monetary policy 1972-1997: a guide using taylor rules. In: Mizen, P. (Ed.)Central Banking, Monetary Theory and Practice: Essays in Honour of Charles Goodhart vol. One. Edward Elgar, Cheltenham, UK, pp. 195-216.

Sargent, T.J., Wallace, N., 1981. Some unpleasant monetary arithmetic. Q. Rev. 1-17 (Federal Reserve Bank of Minneapolis, Fall).

Sims, C.A., 1994. A simple model for the study of the price level and the interaction of monetary and fiscal policy. Economic Theory 4, 381-399.

Sims, C.A., 1997. Fiscal Foundations of Price Stability in Open Economies. mimeo. Yale University.

Smith, A., 1993. Estimating nonlinear time-series models using simulated vector autoregressions. J. Appl. Econ. 8, S63-S84. 
Tanner, E., Ramos, A.M., 2003. Fiscal sustainability and monetary versus fiscal dominance: evidence from Brazil, 1991-2000. Appl. Econ. 35, 859-873.

Wickens, M.R., 1982. The efficient estimation of econometric models with rational expectations. Rev. Econ. Stud. 49 (1), 55-67 (January).

Woodford, M., 1998a. Doing without money: controlling inflation in a post-monetary world. Rev. Econ. Dyn. 1 (1), 173-219.
Woodford, M., 1998b. Control of the public debt: a requirement for price stability? In: Calvo, G., King, M. (Eds.), The Debt Burden and its Consequence for Monetary Policy. Palgrave Macmillan, UK, pp. 117-158

Woodford, M., 2001. Fiscal requirements for price stability. J. Money Credit Bank. 33 (3), 669-728. 